\title{
COMPARISON OF DYNAMIC CHARACTERISTICS FOR AN INFLATABLE SOLAR CONCENTRATOR IN ATMOSPHERIC AND THERMAL VACUUM CONDITIONS
}

\author{
Kara N. Slade * \\ Department of Mechanical Engineering \\ School of Engineering \\ Duke University \\ Durham, NC 27708
}

\author{
Michael L. Tinker ** \\ Structural Dynamics and Loads Group/ED21 \\ Structures, Mechanics, and Thermal Department \\ NASAMarshall Space Flight Center \\ Huntsville, AL 35812
}

\author{
John O. Lassiter $\dagger$ and Robert Engberg $\ddagger$ \\ Structural and Dynamics Testing Group/ED27 \\ Structures, Mechanics, and Thermal Department \\ NASA/Marshall Space Flight Center \\ Huntsville, AL 35812
}

\begin{abstract}
Dynamic testing of an inflatable solar concentrator structure in a thermal vacuum chamber as well as in ambient laboratory conditions is described in detail. Unique aspects of modal testing for the extremely lightweight inflatable are identified, including the use of a noncontacting laser vibrometer measurement system. For the thermal vacuum environment, mode shapes and frequency response functions are compared for three different test article inflation pressures at room temperature. Modes that persist through all the inflation pressure regimes are identified, as well as modes that are unique for each pressure. In atmospheric pressure and room temperature conditions, dynamic measurements were obtained for the expected operational inflation pressure of 0.5 psig. Experimental mode shapes and frequency response functions for ambient conditions are described and compared to the $0.5 \mathrm{psig}$ results from the thermal vacuum tests.

Only a few mode shapes were identified that occurred in both vacuum and atmospheric environments. This somewhat surprising result is discussed in detail, and attributed at least partly to 1.) large differences in modal damping, and 2.) significant differences in the mass of air contained by the structure, in the two environments. Results of this investigation point out the necessity of

\footnotetext{
* Doctoral Candidate; Student Member of ASME Senior Member AIAA

†Aerospace Technologist, Structural Dynamics; Senior Member AIAA Member AIAA

Copyright $\theta 2000$ by the American Institute of Aeronautics and Astronautics, Inc. No copyright is asserted in the United States under Title 17, U.S. Code. The U.S. government has a royalty-free license to exercise all rights under the copyright claimed herein for Govemmental purposes. All other rights are reserved by the copyright owner.
}

**Aerospace Technologist, Structural Dynamics;

$\ddagger$ Aerospace Technologist, Structural Dynamics;
\end{abstract}

testing inflatable space structures in vacuum conditions before they can be launched. Ground testing in atmospheric pressure is not sufficient for predicting on-orbit dynamics of non-rigidized inflatable systems.

\section{Introduction and Background}

Inflatable structures have been the subject of renewed interest in recent years for space applications such as communications antennae, solar thermal propulsion, and space solar power. A major advantage of using inflatable structures in space is their extremely light weight. This makes inflatables a perfect match for solar thermal propulsion because of the low thrust levels available. An obvious second advantage is on-orbit deployability and subsequent space savings in the launch configuration. A recent technology demonstrator flight for inflatable structures was the Inflatable Antenna Experiment (IAE) that was deployed on orbit from the Shuttle Orbiter. Although difficulty was encountered in the inflation/deployment phase, the flight was successful overall and provided valuable experience in the use of such structures (Ref. 1).

The Solar Orbital Transfer Vehicle (SOTV), discussed in Ref. 2 , is a planned technology demonstrator flight for solar thermal propulsion. The basic concept behind solar thermal propulsion is to utilize sunlight or solar energy as a means of heating a working fluid (propellant) to provide thrust at increased specific impulse. As described in Ref. 3, thrust is produced by expanding the heated propellant through a nozzle. No combustion occurs, and the thrust level is low. For this reason, solar thermal propulsive systems are mainly applicable for orbital transfer vehicles.

Another technology demonstration program for solar thermal propulsion is the Solar Thermal Upper Stage (STUS), which is described in Refs. 4-6. The engine system envisioned for the STUS is designed to utilize hydrogen propellant to produce a thrust level of about $2 \mathrm{lbf}$. Two inflatable parabolic collectors could be used that would be rotated and gymballed for focusing sunlight into an absorber cavity (Fig. 1, from Ref. 6). The collectors would be inflated after separation of the upper stage from the launch vehicle. 
$\therefore$ mumber of ofler investigators have considered the use of intlatible structures for space applications. Perhaps the carliest was Frei Ong (Ret. 7), who in 1962 published ide:as for inhlated tubular frames for use in structures such as orbiting platforms. A more recent proposed applicarion involves the use of intlatable bean segments to replace solid segments of the Space Shutte remote manipulator system and thus reduce storage space and inertia of the arm (Ref. 8).

Several papers on static structural analysis of inflated cylinders have been written, describing different techniques such as linear shell theory, and nonlinear and variational methods (Refs. 9-17). Additional work of signiticance involves rigidization of inflated beam structures. One proposed concept is the use of injected foam which fills the cylindrical beam cross-section, subsequently hardens and thus rigidizes the structure. This approach is discussed in Ref. 18.

Very little work had been done in dynamics testing and analysis of inflatable structures until recent years. In 1988 Leonard (Ref. 19) indicated that elastic beam bending modes could be utilized in approximating lower-order frequencies of inflatable beams. Main, et al. wrote a very significant 1995 paper describing results of modal tests of inflated cantilever beams and the determination of effective material properties (Ref. 20). Changes in material properties for different pressures were also discussed, and the beam model was used in a more complex structure. The paper demonstrated that conventional finite element analysis packages could be very useful in the analysis of complex inflatable structures. Reference 21 describes an investigation of the dynamics of polyimide thin-film inflated cylinders, and Refs. 22-27 discuss recent dynamic tests and potential applications of inflatable solar concentrators.

\section{Description of Inflatable Solar Concentrator Investigated in the Current Study}

In Fig. 2, a prototype inflatable solar concentrator is shown that consists of a torus/lens assembly supported by three struts. This concentrator is constructed of Kapton polyimide film, with epoxy as the primary adhesive for joints. In practical applications, the Fresnel lens or reflector of such a concentrator assembly would focus sunlight into a collector near the fixed ends of the struts. Solar energy stored in the collector could be utilized to heat a propellant as described previously. The inflatable struts shown in Fig. 2 are attached to a base plate by means of three cylindrical appendages. These hollow appendages also allow inflation of the concentrator assembly through air hoses connected at each strut.

Inflatable structures in general are extremely lightweight and the solar concentrator described in this paper is no exception. The inflatable part of the concentrator was only $15 \%$ of the total weight; the remaining weight was due to the aluminum interface plate.

\section{Test Configurations and Results}

\section{Modal Test Configuration and Procedures in Thermal Vacuum Conditions}

Due to 1.) current limitations in the accuracy of finite element models of inftatable structures, and 2.) lack of understanding of the behavior of intlatables in space, it was determined that the solar concentrator modal survey tests should be conducted in a thermal vacuum chamber. Such an approach allows testing in environments replicating orbital conditions as nearly as possible. Testing was done in N.ASA Marshall Space Flight Center's X-Ray Calibration Facility (XRCF). The facility includes a thermally controlled vacuum chamber 22.9 meters ( $75 \mathrm{ft}$ ) long and 7.3 meters $(20 \mathrm{ft})$ in diameter, large enough to hold anything that will fit into the Space Shuttle's cargo bay. The vacuum chamber has both liquid nitrogen cooled panels and heater panels for simulating deep space operating conditions and for providing accurate thermal stability. Connecting the 500 meters $(1700 \mathrm{ft})$ between the X-ray sources and the instrument chamber is the guide rube. Thermal control range of the chamber is $-160^{\circ} \mathrm{F}$ to $+160^{\circ} \mathrm{F}$ and the lowest vacuum that can be obtained is $10^{-7}$ Torr. Figure 3 shows the inflatable concentrator in the XRCF chamber.

Due to high flexibility of the polyimide film at any location on the inflated part of the concentrator, it was decided to utilize single-point random shaker excitation at a location on the interface plate (Figure 2) as opposed to exciting the structure directly on the inflatable surface. This decision to provide excitation at the interface plate meant that the concentrator had to be suspended in a freefree boundary condition. A soft stainless steel spring system was designed to provide the lowest rigid body frequencies possible, and yet have the strength to suspend the test article above the floor of the vacuum chamber. Metal springs as opposed to soft rubber "bungee" cords were required for protection of the chamber interior.

Due to the fact that any commercially available accelerometer, no matter how lightweight, would mass-load the inflated components and the lens of the test article, a non-contacting vibration measuring device was needed. In addition, the limited number of cable feedthroughs in the thermal-vacuum chamber for accelerometers and the fact that adhesives could not be used in the chamber due to their outgassing characteristics further demonstrated the need for non-contact measurements. A scanning laser vibrometer was thus employed for this test. Figure 4 shows the approximate location of the laser vibrometer relative to the test article and the vacuum chamber. The laser had to be aimed at the inflatable structure through a porthole at the end of the guide rube, which was the only location outside the chamber from which the test article could be viewed directly.

Response measurements on the surface of the inflatable concentrator were complicated by the fact that the polyimide material is optically transparent, allowing much of the laser light to pass through the test article. In addition, 
the litser beam should be as close to perpendicular as possible with respect to the test article surface in order to minimize any degradation in vibrometer measurements. This is truc because the vibrometer is designed to meatsure the est article motion along the direction of the laser beam, and it the laser is not truly perpendicular to the surtice, only a component of the real motion is measured. All these considerations required the use of surface treatments to facilitate testing. Sandblasted aluminum reflective tape was mounted at all points (struts and torus) where the measurements were to be taken. On the inflatable torus the reflective tape was formed in the shape of "corner cubes" whose perpendicular sides were aligned with the $X$ and $Y$ axes. The surface preparations are shown in Figure 5.

Even with use of the surface preparations and corner cubes, errors were encountered in the measurements since the laser beam could not be directly aligned with the test article coordinate system for most response points. Again, this was due to the fact that the test article was visible from only one location outside the chamber, the glass porthole.

Testing in the XRCF thermal vacuum chamber presented a number of difficulties, including limited accessibility to the test article for acquiring measurements. As described in the previous paragraph, dynamic response measurements could only be taken with the laser vibrometer through the single glass porthole. This limitation, along with the impracticality of suspending the test article from the side, prevented any measurements perpendicular to the plane of the torus/lens of the concentrator ( $Z$ direction). Mode shapes could only be obtained for the $\mathrm{X}$ and $\mathrm{Y}$ directions, which were parallel to the plane of the torus/lens assembly.

Initially the porthole direction was along the $\mathrm{X}$ axis of the concentrator test article. Data was taken in this initial configuration at $70^{\circ} \mathrm{F}$ for three inflation pressures of the concentrator: $0.5,0.25$, and $0.75 \mathrm{psig}$, respectively. Then the cryogenic portion of the test was conducted at a temperature of $-55^{\circ} \mathrm{F}$ and concentrator inflation pressure of 0.5 psig. In the second testing configuration, the test article was rotated $90^{\circ}$ such that the $\mathrm{Y}$ axis was aligned with the porthole direction, while the shaker orientation was unchanged. The four test conditions described in this paragraph were repeated for the $\mathrm{Y}$ direction.

\section{Discussion of Test Data for Thermal Vacuum Conditions}

Modal parameters were successfully identified for the three pressures and $70^{\circ} \mathrm{F}$ test conditions. Twelve, 10, and 11 mode shapes with their frequencies and damping were identified for the $0.5 \mathrm{psig}, 0.25 \mathrm{psig}$, and the $0.75 \mathrm{psig}$ pressures, respectively. The modal properties for the nominal $70^{\circ} \mathrm{F}$ temperature conditions (Tables 1-3) showed characteristics previously seen in previous inflatable concentrators modal tests done at MSFC, primarily the heavy ( > $1 \%$ ) damping of lower order mode shapes. The cryogenic test case $\left(0.5 \mathrm{psig},-50^{\circ} \mathrm{F}\right)$ yielded lower damping levels in the lower order modes, as seen in Table 4 . As expected, modal frequencies increased with increases in test article pressure. Inspection of mode shapes for each pressure configuration showed that some modes are very similar from one pressure to the next, but other moles are "orphans", or unique for the pressure level. This observation points out the impretance of carclully determining the operational on-orbit intlation pressure for he strecture, as well as the need for testing in nonoperational conditions. Figures 6 and 7 show two mode shapes for the $0.5 \mathrm{psig} / 70^{\circ} \mathrm{F}$ case, occurring at $5.66 \mathrm{~Hz}$ (third mode) and $27.70 \mathrm{~Hz}$ (seventh mode).

As seen in Figures 11-13, the frequency response functions (FRF's) were less than optimal, exhibiting a nuticeable amount of noise (closely spaced, low amplitude peaks) between the major resonant peaks. Possible reasons for this noise will be discussed in the next paragraph. In general, the response functions showed the high damping and close modal coupling seen in the previous tests of inflatable concentrators. Response function measurements during the low temperature $\left(-55^{\circ} \mathrm{F}\right)$ configuration were degraded due to condensation on the porthole glass, changes in the polyimide film (increased brittleness at very low temperature), and possible loss of shaker performance. As a consequence, the "cryogenic FRF's" could not be used in the modal parameter identification process.

Response functions (FRF's) from all test configurations had a considerable amount of noise (as described in the previous paragraph) that is possibly attributed to three problems or conditions. One is the possibility of inadequate force distribution through the concentrator. The high flexibility and high damping of the inflatable components may have hindered the propagation of energy through the structure from the interface plate. No attempts to excite the concentrator at a location on the inflatable surface were made due to the expected local flexibilities causing inadequate input power spectra. A second possible condition contributing to noisy FRF's is due to limitations of the shaker, where input power substantially decreased below $2 \mathrm{~Hz}$. This caused an additional reduction in force input into the inflatable components in this frequency range. Force levels for this modal survey test averaged around 25 mlbf rms. The third condition causing or contributing "noise" in the FRF's is the likelihood of local shell modes being present in the bandwidth of the global modes of the concentrator.

A Modal Assurance Criterion (MAC) matrix for each set of mode shapes was determined in order to verify the independence and orthogonality of the modes. Typically, off diagonals of 0.1 or less are required in order to verify the independence of one mode from another and verify the quality of the measured mode shapes. However due to 1.) symmetry and non-linearity of the structure, 2.) highly damped and coupled mode shapes, 3.) possible inadequate excitation to the structure, and 4.) possible inadequate spatial resolution due to the limited number of measurement points, it was decided that any mode shape with an off diagonal of 0.4 or less would be considered an acceprable mode if it met certain conditions. These conditions were that the mode must: a.) be global with respect to its deformations, b.) have a stable pole at low model orders with continued stability at higher model orders, and c.) have 
a distinctive peak in the mode indicator fimetion corresponding to the stable poles.

On the basis of eomparisons between lest data and madel predictions, it was suspected that the suspension system coupled with the intlatable concentrator modes. Additional testing continmed the coupling of the suspension system, and the springs had to be included in the model as accurately as possible. Such test-article-to-suspension coupling cannot be avoided in free-tree tests of lightweight and highly flexible in thatable structures.

\section{Modal Survey Testing in Atmospheric Pressure}

The purpose of testing the inflatable concentrator in a laboratory in atmospheric pressure and room temperature was twofold: 1.) To compare dynamic characteristics of the structure in ambient and vacuum environments, and 2.) To provide measurements perpendicular to the plane of the torus/lens assembly ( $Z$ direction), including the Fresnel lens simulator. Recall that the $Z$ measurements could not be obtained in the thermal vacuum chamber due to limitations on the laser vibrometer field-of-view and the impracticality of mounting the test article from the side.

Test article suspension configuration, strut and torus measurement point locations, and shaker location and orientation (for excitation in the $X$-direction) were the same as for the thermal vacuum tests. Of course, for the $Z$ direction excitation, the shaker was reoriented. The guiding purpose in this testing was to replicate as nearly as possible the test configuration utilized in the vacuum chamber, in order to make valid comparisons of the $\mathrm{X}$ - and $\mathrm{Y}$-direction measurements. Figure 8 shows the inflated concentrator mounted in the test fixture, with the shaker and suspension springs clearly visible at the aluminum interface plate.

Visual checkout of the test article rigid body modes on the suspension system revealed that vertical ( $Z$ or "plunge" mode) and pendulum frequencies (both $X$ and $Y$ axes) were approximately $0.40 \mathrm{~Hz}$. Obviously, this verifies the suspected coupling of the lowest frequency modes with the suspension system that was mentioned in the discussion of vacuum test results. This coupling was further verified at the beginning of the ambient testing by attaching lumped masses to the springs and observing changes in the frequency response. In order to better characterize the spring motion in the mode shapes, measurements points were added at four locations on one of the springs. Coupling of this nature is simply unavoidable in free-free testing of extremely lightweight and flexible inflatable (non-rigidized) structures. It appears that even with the best suspension system design, the flexibility of the test article will be on the same order as that of the suspension system.

As described earlier in the paper, the decision to do freefree testing was based on the difficulty of exciting the structure on the inflatable surface, and the perceived necessity of providing excitation at the aluminum interface plate. The lesson learned in this approach, in light of the ever-present suspension coupling with the inflatable, is that constrained boundary conditions should be used in future testing, and that the problem of exciting on the inflatable surface is less severe than the coupling problem.
Mode shapes and frepkency response data were oblained for the $X, Y$, and $Z$ directions at 0.5 psig and approximalely $7)^{\circ} \mathrm{F}$ averige emperature. It was thought that atmospherie esits at only the operational intlation pressure woulat be sutficient for comparison to the vicumm environment. The test data is discussed in the next section.

\section{Discussion of Test Results for the Atmospheric Pressure Environment}

Ten modes were identitied for the $X$-axis shaker excitation configuration, and 12 modes were measured for the $Z$ excitation case. Going into the test, it was expected that many of the same modes would be excited in both shaker orientations. However, inspection of the modes revealed essentially two different sets. Strut-dominated modes appear in the frequency range above about $25 \mathrm{~Hz}$ in both cases, but even these modes are considerably different. Figures 9 and 10 show two such modes from the $X$ and $Z$ excitations, respectively. It is possible that the combined influences of the suspension system and shaker-imposed constraints are the cause of the lack of similarity between the $X$ and $Z$ excitation cases.

Tables 5 and 6 list the modal frequencies and damping for $\mathrm{X}$ and $\mathrm{Z}$ excitations, respectively. The clear observation to be made is that the first few modes in each case are very heavily damped, and in fact all the modes have high damping. In general, this observation has been made in all dynamic testing of inflatable structures conducted at MSFC.

Additional observations of the modal properties in ambient conditions can be made related to the behavior of the torus and lens simulator. As described earlier in the paper, Z-direction measurements (direction perpendicular to the torus/lens plane) could not be made in the vacuum chamber. Several of the X-excitation modes, for example $13.06 \mathrm{~Hz}$ and $21.96 \mathrm{~Hz}$, show considerable Z-bending of the torus. Also, most of the modes for both excitation cases have extensive $Z$-direction response of the lens simulator. These characteristics must be carefully considered in design of inflatable structures for spaceflight, in order to achieve desired performance of the optical element.

Finally, MAC matrices were computed for the test modes in each of the $X$ and $Z$ excitation cases to check their independence. In Table 7, the MAC matrix for the Xdirection excitation is shown. It can be seen that the offdiagonal terms are high in a several instances. This is likely due to the symmetry of the structure and resulting similarity of some modes, Another contributing factor could be possible insufficient spatial resolution - perhaps additional measurement points would improve the MAC. However, as stated in the discussion of vacuum-condition data, modes with high off-diagonals are still accepted as valid independent modes as long as the parameter identification conditions on global character and stability of poles at both low and high model orders are met. 


\section{Explanations of Differences Observed in Vacuum and Ambient Conditions}

\section{Frequency Response and Normal Modes}

The normal modes of vibration were compared numerically using the Modal Assurance Criterion (MAC) computation. The MAC between two vectors, $V_{t}$ and $V_{s}$, is detined by:

$$
M A C_{r, s}=\frac{\left|V_{r} V_{s}^{*}\right|^{2}}{\left(V_{r}{ }^{T} V_{r}^{*}\right)\left(V_{s}^{T} V_{s}^{*}\right)}
$$

Given this definition, then, a set of identical nomal modes would generate a matrix which contained diagonal terms of 1.0 and off-diagonal terms of 0.0 . When the test results were compared to each other, this was not found to be the case. Only two modes were found to correlate with diagonal MAC values greater than 0.5. As seen in Table 8, which compares the eigenvectors from the 0.5 psig case in the vacuum test to those from the ambient test, also at 0.5 psig, these modes were the $5.38 / 5.66 \mathrm{~Hz}$ mode and the 13.06/13.79 Hz mode.

Table 8 also shows a number of off-diagonal entries which are appreciably greater than zero, indicating a large degree of similarity between modes in an individual test case. This is borne out by the results of calculating the MAC matrix for the ambient test case against itself. Table 7 indicates that the nonzero off-diagonal terms are present even in this case. This leads to the conclusion that some of the experimentally determined normal modes of the structure in a given test case have enough similarity to each other that they are not completely orthogonal. Tables 9 and 10 show that across differing pressurization levels in the vacuum test, some modes correlate very strongly and others do not.

Also, the frequency response functions (FRF) for the test cases were compared. As may be expected by the previous results from the MAC calculations, the peaks which most closely corresponded occurred in the $5.7 \mathrm{~Hz}$ range and the $13.5 \mathrm{~Hz}$ range. Figure 11 shows the result for ambient and vacuum testing at 0.5 psig, Fig. 12 for vacuum testing at 0.25 psig, and Fig. 13 for vacuum testing at 0.75 psig. In all of these figures, the solid line depicts the result in the vacuum test, and the dashed line that of the ambient test. The marked difference in frequency peaks occurring in the higher frequency region is especially notable. Also, it is important to observe that there is not a significant vertical difference between the baseline in the vacuum test and the baseline in the ambient test. From this, it may be concluded that the differences in mass between the test cases caused by the presence of more or less air in the inflatable is not a major contributing factor to the differences in FRF's.

\section{Damping}

Another comparison may be drawn from examining the results of ealculation of modal damping ratios. Figures it through 17 show plots of damping vs. frequency, where the + symbols indicate the ambient test and the o symbols the vacuum test. Figure 14 indicates the result for the $0.5 \mathrm{psig}$ vacuum test and the ambient test, Fig. 15 at 0.25 psig. Fig. 16 at $0.75 \mathrm{psig}$, and Fig. 17 the cryogenic vacuum test at a pressure level of 0.5 psig and a temperature level of $\mathrm{T}=$ $50^{\circ} \mathrm{F}$. Consistently in these plots, we see that the ambient curve is shifted up and to the right from the vacuum curve, indicating a higher level of modal damping in the ambient case. This is to be expected, as the ambient conditions provide damping in the form of air resistance, which the vacuum conditions remove. It is also noteworthy that in the cryogenic test, shown in Fig. 17, the damping level is lower than that of the other vacuum tests. This indicates that the lowered temperature increases the brittleness of the structure, reducing the damping level.

\section{Summary}

Modal testing was conducted on the Pathfinder 3 test article of the Shooting Star Experiment. Tests were conducted under ambient laboratory conditions and in thermal vacuum, both at room temperature and in cryogenic conditions. The test results, and analysis of the results, indicate that there are significant differences between the performance of the structure in ambient and vacuum conditions. MAC calculations show good correspondence between ambient and vacuum for two modes, the others were not well correlated. Comparison of frequency response functions confirms these correlations. Also, the damping levels found in the ambient test were higher than those of the vacuum test. The results of this study point to a need to conduct vacuum modal surveys of inflatable articles intended for space applications in order to ensure that onorbit behavior will be well replicated in the test environment.

\section{Acknowledgments}

The authors wish to thank Larry Bradford at United Applied Technologies in Huntsville, AL for the construction of the test articles used in this experiment, and the X-Ray Calibration Facility at Marshall Space Fight Center for providing the vacuum facilities in which the modal testing was conducted. 


\section{References}

1. Frecland, Robert E.." Intlatable Antenna Flighlt Experiment Experiences". $V_{i}$ S I Solar Thermal Propulsion Workshor Proceedings, NAS A Marshall Space Flight Center, Huntsville, AL. March 19-20, 1997.

2. Partch, Russell, "Solar Thermal Propulsion Program at Phillips Lab", NASA Sular Thermal Propulsion Workshop Proceedings. NASA Marshall Space Flight Center, Huntsville, AL March 19-20, 1997.

3. Stewart, Jesse F.. and Martin, James A.,"Dual Fuel Solar Thermal Stage: Ideal Analysis", Journal of Spacecraft and Rockets, Vol. 33, No. 5, 1996, pp. 752754.

4. Patel, S., and Emrich, W. J., Jr., "Solar Thermal Upper Stage (STUS) Feasibility Study", Proceedings of ASME/JSME/JSES International Solar Energy Conference, Maui, HI, March 1995.

5. Hawk, C.W., Adams, Alan M., et al., "Conceptual Design of a Solar Thermal Upper Stage (STUS) Flight Experiment", AIAA Paper 95-2842.

6. Curtis, Leslie, "NASA Solar Thermal Propulsion Project", NASA Solar Thermal Propulsion Workshop Proceedings, NASA Marshall Space Flight Center, Huntsville, AL, March 19-20, 1997.

7. Otto, Frei, Tensile Structures, Massachusetts Institute of Technology, Cambridge, MA, 1962.

8. McCarty, L.H., "Inflatable Arm Segments May Lighten Shuttle's Manipulator System", Design News 46(4).pp. 150-151.1990.

9. Leonard, R.W., Brooks, G.W., and McComb, H.G., Jr., "Structural Considerations of Inflatable Reentry Vehicles", NASA Technical Note D-457, 1960.

10. Topping, A.D., "Shear Deflections and Buckling Characteristics of Inflated Members", Joumal of Aircraft 1(5). DR. 289-293.1964.

11. Bulson, P.S., "Design Principles of Pneumatic Structures", Structural Engineering. 51(6). pp. 209-215. 1973.

12. Douglas, W.J., "Bending Stiffness of an Inflated Cylindrical Cantilever Beam", AIAA Joumal, 7(7). pp. 1248-1253.1969.

13. Steeves, E.C., "A Linear Analysis of the Deformation of Pressure Stabilized Tubes", U.S. Army Natick Laboratories Report, AD/A-006 493, NTIS, N7532513.

14. Fichter, W.B., "A Theory for Inflated Thin-Wall Cylindrical Beams", NASA Technical Note D-3466, June 1966.

15. Comer, R.L., and Levy, S., "Deflections of an Inflated Circular-Cylinder Cantilever Beam", AIAA Joumal. 1(7), pp. 1652-1655, 1963.

16. Webber, J.P.H., "Deflections of Inflated Cylindrical Cantilever Beams Subjected to Bending and Torsion", Aeronautical Joumal 86(858) . pR. 306-312. 1982

17. Main, J.A., Peterson, S.W., and Strauss, A.M., "Load-Deflection Behavior of Space-Based Intlatable

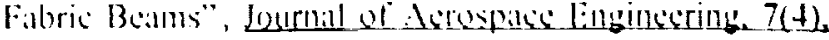
$194+4$

18. Hobbs, K.P., Jr., Smith. Suzanne W., and Main. John A., "Pust-Flight Testing and Analysis of Zero-G Foim Rigidized Struts", Processlings of the 40th Sencturss, Structural Dymamics and Materials Conferences April 12-16, 1999. St. Louis, MO.

19. Leonard, J.W., Tension Siructures McGraw-Hill, New York, 1988.

20. Main, J.A., Carlin, R.A., Garcia, E., Peterson, S.W., and Strauss, A.M., "Dynamic Analysis of SpaceBased Inflated Beam Structures", Journal of the Acoustical Society of America, 97(2). pD. 1035-1045. Feb. 1995.

21. Slade, Kara N., and Tinker, Michael L., "Analytical and Experimental Investigation of the Dynamics of Polyimide Inflatable Cylinders", AIAA-99. 1518. Proceedings of the 40th Structures. Structural Dynamics, and Materials Conference, April 12-15, 1999, St. Louis, MO.

22. Tinker, Michael L., "Passively Adaptive Inflatable Structure for the Shooting Star Experiment", AIAA-981986, Proceedings of the 39th Structures. Structural Dvnamics, and Materials Conference, April 20-23, 1998, Long Beach, CA.

23. Lassiter, John, "Shooting Star Experiment Prototype Inflatable Strut/Torus Assembly Modal Survey", ED73(97-69), NASA Marshall Space Flight Center, Huntsville, AL, June 1997.

24. Engberg, Robert, and Lassiter, John, "Shooting Star Experiment, Pathfinder 2, Inflatable Concentrator Modal Survey in Vacuum Conditions", Dynamics Test Branch, Marshall Space Flight Center Test Report SSEDEV-ED97-120, March, 1998.

25. Engberg, Robert, and Lassiter, John, "Shooting Star Experiment, Pathfinder 3, Inflatable Concentrator Modal Survey in Thermal-Vacuum Conditions", Dynamics Test Branch, Marshall Space Flight Center Test Report SSE-DEV-ED97-115, February, 1998.

26. Engberg, Robert, and Lassiter, John, "Shooting Star Experiment, Pathfinder 3, Inflatable Concentrator Terminator Test, Dynamics Test Branch, Marshall Space Flight Center Test Report SSE-DEV-ED98-046, July, 1998.

27. Lassiter, John O., and Engberg, Robert, "Dynamic Testing of an Inflatable Structure Under Thermal-Vacuum Conditions", AIAA-99-1519, Proceedings of the 40th Structures. Structural Dynamics. and Materials Conference, April 12-15, 1999, St. Louis, MO. 


\begin{tabular}{|c|c|c|}
\hline Mode & $\begin{array}{c}\text { Freq. (Hz) } \\
0.5 \mathrm{psig} / 70^{\circ} \mathrm{F}\end{array}$ & $\begin{array}{c}\text { Damping, \% } \\
0.5 \mathrm{psig} / 70^{\circ} \mathrm{F}\end{array}$ \\
\hline 1 & 0.836 & 15.68 \\
\hline 2 & 3.71 & 4.76 \\
\hline 3 & 5.66 & 3.51 \\
\hline 4 & 11.00 & 1.29 \\
\hline 5 & 13.79 & 0.98 \\
\hline 6 & 26.77 & 0.46 \\
\hline 7 & 27.70 & 1.88 \\
\hline 8 & 34.39 & 0.85 \\
\hline 9 & 35.84 & 2.18 \\
\hline 10 & 39.40 & 2.41 \\
\hline 11 & 41.62 & 0.90 \\
\hline 12 & 43.79 & 1.23 \\
\hline
\end{tabular}

Table 1. Thermal vacuum modal frequencies and percent damping, $0.5 \mathrm{psig} / 70^{\circ} \mathrm{F}$

\begin{tabular}{|c|c|c|}
\hline Mode & $\begin{array}{c}\text { Freq. (Hz) } \\
0.25 \text { psig/70 }\end{array}$ & $\begin{array}{c}\text { Damping, \% } \\
0.25 \text { psig/70 }\end{array}$ \\
\hline 1 & 0.509 & 44.13 \\
\hline 2 & 4.21 & 4.38 \\
\hline 3 & 9.27 & 1.35 \\
\hline 4 & 10.78 & 4.40 \\
\hline 5 & 26.53 & 0.58 \\
\hline 6 & 31.45 & 2.15 \\
\hline 7 & 33.53 & 1.53 \\
\hline 8 & 37.24 & 1.45 \\
\hline 9 & 40.25 & 1.58 \\
\hline 10 & 42.47 & 0.94 \\
\hline
\end{tabular}

Table 2. Thermal vacuum modal frequencies and percent damping, $0.25 \mathrm{psig} / 70^{\circ} \mathrm{F}$

\begin{tabular}{|c|c|c|}
\hline Mode & $\begin{array}{c}\text { Freq. (Hz) } \\
0.75 \mathrm{psig} / 70^{\circ} \mathrm{F}\end{array}$ & $\begin{array}{c}\text { Damping, \% } \\
0.75 \mathrm{psig} / 70^{\circ} \mathrm{F}\end{array}$ \\
\hline 1 & 0.847 & 18.87 \\
\hline 2 & 3.81 & 5.07 \\
\hline 3 & 5.80 & 2.08 \\
\hline 4 & 13.16 & 1.96 \\
\hline 5 & 26.86 & 0.71 \\
\hline 6 & 34.72 & 0.86 \\
\hline 7 & 36.55 & 2.68 \\
\hline 8 & 39.67 & 2.01 \\
\hline 9 & 42.12 & 1.17 \\
\hline 10 & 44.58 & 0.87 \\
\hline 11 & 46.68 & 0.93 \\
\hline
\end{tabular}

Table 3. Thermal vacuum modal frequencies and percent damping, $0.75 \mathrm{psig} / 70^{\circ} \mathrm{F}$ 


\begin{tabular}{|c|c|c|}
\hline Mode & $\begin{array}{c}\text { Freq. }(\mathrm{Hz}) \\
0.5 \mathrm{psig} /-50^{\circ} \mathrm{F}\end{array}$ & $\begin{array}{c}\text { Damping, \% } \\
0.5 \mathrm{psig} /-50^{\circ} \mathrm{F}\end{array}$ \\
\hline 1 & 1.54 & 3.35 \\
\hline 2 & 3.91 & 1.35 \\
\hline 3 & 6.10 & 1.51 \\
\hline 4 & 10.12 & 1.65 \\
\hline 5 & 11.15 & 0.96 \\
\hline 6 & 27.41 & 0.98 \\
\hline 7 & 31.37 & 1.49 \\
\hline 8 & 44.59 & 0.56 \\
\hline
\end{tabular}

Table 4. Cryogenic thermal vacuum modal frequencies and percent damping, $0.50 \mathrm{psig} /-50^{\circ} \mathrm{F}$

\begin{tabular}{|c|c|c|}
\hline Mode & $\begin{array}{c}\text { Freq. } \\
(\mathrm{Hz})\end{array}$ & $\begin{array}{c}\text { Modal } \\
\text { Damping, \% }\end{array}$ \\
\hline 1 & 2.34 & 14.67 \\
\hline 2 & 5.38 & 15.66 \\
\hline 3 & 8.36 & 6.92 \\
\hline 4 & 13.06 & 3.20 \\
\hline 5 & 21.96 & 1.88 \\
\hline 6 & 24.73 & 2.49 \\
\hline 7 & 32.34 & 2.08 \\
\hline 8 & 35.93 & 1.61 \\
\hline 9 & 40.59 & 0.81 \\
\hline 10 & 45.32 & 1.61 \\
\hline
\end{tabular}

Table 5. Atmospheric modal frequencies and percent damping, X-excitation, $0.5 \mathrm{psig} / 70^{\circ} \mathrm{F}$

\begin{tabular}{|c|c|c|}
\hline Mode & $\begin{array}{c}\text { Freq. } \\
(\mathrm{Hz} .)\end{array}$ & $\begin{array}{c}\text { Modal } \\
\text { Damping, \% }\end{array}$ \\
\hline 1 & 3.57 & 17.62 \\
\hline 2 & 5.50 & 9.59 \\
\hline 3 & 8.17 & 8.48 \\
\hline 4 & 13.86 & 5.74 \\
\hline 5 & 16.52 & 5.37 \\
\hline 6 & 18.55 & 2.93 \\
\hline 7 & 24.58 & 1.17 \\
\hline 8 & 25.79 & 2.09 \\
\hline 9 & 28.38 & 2.89 \\
\hline 10 & 32.18 & 2.38 \\
\hline 11 & 34.48 & 1.90 \\
\hline 12 & 36.39 & 2.53 \\
\hline
\end{tabular}

Table 6. Atmospheric modal frequencies and percent damping, Z-excitation, $0.5 \mathrm{psig} / 70^{\circ} \mathrm{F}$ 


\begin{tabular}{|c|c|c|c|c|c|c|c|c|c|c|}
\hline $\begin{array}{c}\text { Frey. } \\
(H 2 .)\end{array}$ & 2.34 & 5.38 & 8.36 & 13.06 & 21.96 & 24.73 & 32.34 & 35.93 & 40.59 & 45.32 \\
\hline 2.34 & 1.00 & 0.01 & 0.10 & 0.08 & 0.04 & 0.13 & 0.00 & 0.02 & 0.01 \\
\hline 5.38 & 0.01 & 1.00 & 0.18 & 0.41 & 0.33 & 0.29 & 0.01 & 0.03 & 0.01 \\
\hline 8.36 & 0.10 & 0.18 & 1.00 & 0.08 & 0.15 & 0.16 & 0.00 & 0.00 & 0.02 \\
\hline 13.06 & 0.08 & 0.41 & 0.08 & 1.00 & 0.26 & 0.35 & 0.00 & 0.01 & 0.00 & 0.04 \\
\hline 21.96 & 0.04 & 0.33 & 0.15 & 0.26 & 1.00 & 0.19 & 0.01 & 0.08 & 0.01 \\
\hline 24.73 & 0.13 & 0.29 & 0.16 & 0.35 & 0.19 & 1.00 & 0.12 & 0.31 & 0.07 \\
\hline 32.34 & 0.00 & 0.01 & 0.00 & 0.00 & 0.01 & 0.12 & 1.00 & 0.08 & 0.17 \\
\hline 35.93 & 0.02 & 0.03 & 0.00 & 0.01 & 0.08 & 0.31 & 0.08 & 1.00 & 0.03 \\
\hline 40.59 & 0.01 & 0.01 & 0.02 & 0.00 & 0.01 & 0.07 & 0.17 & 0.27 \\
\hline 45.32 & 0.00 & 0.02 & 0.11 & 0.04 & 0.03 & 0.00 & 0.04 & 0.27 & 0.00 \\
\hline
\end{tabular}

Table 7. MAC Matrix: Ambient test, 0.5 psig (rows) vs. ambient test, 0.5 psig (columns)

\begin{tabular}{|c|c|c|c|c|c|c|c|c|c|c|c|c|}
\hline $\begin{array}{l}\text { Freq. } \\
(\mathrm{Hz})\end{array}$ & $\begin{array}{c}3 \\
0.84\end{array}$ & 3.71 & 5.66 & 11.00 & 13.79 & 26.77 & 27.70 & 34.39 & 35.84 & 39.40 & 41.62 & 43.79 \\
\hline 2.34 & 0.13 & 0.00 & 0.00 & 0.11 & 0.00 & 0.00 & 0.02 & 0.00 & 0.06 & 0.00 & 0.00 & 0.00 \\
\hline 5.38 & 0.05 & 0.07 & 0.83 & 0.22 & 0.45 & 0.00 & 0.02 & 0.00 & 0.03 & 0.01 & 0.00 & 0.00 \\
\hline 8.36 & 0.16 & 0.07 & 0.24 & 0.05 & 0.26 & 0.00 & 0.10 & 0.01 & 0.17 & 0.00 & 0.00 & 0.00 \\
\hline 13.06 & 0.11 & 0.04 & 0.64 & 0.23 & 0.51 & 0.00 & 0.09 & 0.03 & 0.09 & 0.01 & 0.00 & 0.00 \\
\hline 21.96 & 0.20 & 0.03 & 0.48 & 0.00 & 0.15 & 0.02 & 0.02 & 0.00 & 0.03 & 0.00 & 0.00 & 0.06 \\
\hline 24.73 & 0.16 & 0.04 & 0.33 & 0.01 & 0.15 & 0.05 & 0.17 & 0.11 & 0.11 & 0.16 & 0.00 & 0.01 \\
\hline 32.34 & 0.04 & 0.00 & 0.00 & 0.17 & 0.11 & 0.01 & 0.01 & 0.02 & 0.00 & 0.08 & 0.11 & 0.01 \\
\hline 35.93 & 0.06 & 0.01 & 0.02 & 0.06 & 0.00 & 0.08 & 0.08 & 0.07 & 0.03 & 0.21 & 0.02 & 0.03 \\
\hline 40.59 & 0.03 & 0.00 & 0.00 & 0.23 & 0.12 & 0.00 & 0.00 & 0.00 & 0.00 & 0.10 & 0.02 & 0.12 \\
\hline 45.32 & 0.01 & 0.00 & 0.00 & 0.28 & 0.22 & 0.01 & 0.00 & 0.00 & 0.03 & 0.08 & 0.01 & 0.12 \\
\hline
\end{tabular}

Table 8. MAC Matrix: Vacuum test, $0.5 \mathrm{psig}$ (rows) vs. ambient test, $0.5 \mathrm{psig}$ (columns) 


\begin{tabular}{|c|c|c|}
\hline $\begin{array}{c}\text { Modal frequency, } \\
0.5 \text { psig test }\end{array}$ & $\begin{array}{c}\text { Modal frequency, } \\
0.25 \text { psig test }\end{array}$ & $\begin{array}{c}\text { Correlative diagonal MAC } \\
\text { value }\end{array}$ \\
\hline 0.84 & - & - \\
\hline 3.71 & - & - \\
\hline 5.66 & 4.21 & 0.67 \\
\hline 11.00 & 9.27 & 0.78 \\
\hline 13.79 & - & - \\
\hline 26.77 & 26.53 & 0.91 \\
\hline 27.70 & - & - \\
\hline 34.39 & 33.53 & 0.75 \\
\hline 35.84 & - & - \\
\hline 39.40 & - & - \\
\hline 41.62 & 40.25 & 0.77 \\
\hline 43.79 & 42.47 & 0.72 \\
\hline
\end{tabular}

Table 9. Strongly correlated modes across pressure levels for vacuum test, 0.5 psig and $0.25 \mathrm{psig}$

\begin{tabular}{|c|c|c|}
\hline $\begin{array}{c}\text { Modal frequency, } \\
0.5 \text { psig test }\end{array}$ & $\begin{array}{c}\text { Modal frequency, } \\
0.75 \text { psig test }\end{array}$ & $\begin{array}{c}\text { Correlative diagonal MAC } \\
\text { value }\end{array}$ \\
\hline 0.84 & - & - \\
\hline 3.71 & 3.81 & 0.93 \\
\hline 5.66 & 5.80 & 0.94 \\
\hline 11.00 & 13.16 & 0.75 \\
\hline 13.79 & - & - \\
\hline 26.77 & 26.86 & 0.98 \\
\hline 27.70 & - & - \\
\hline 34.39 & 34.72 & 0.98 \\
\hline 35.84 & 36.55 & 0.63 \\
\hline 39.40 & - & - \\
\hline 41.62 & - & - \\
\hline 43.79 & 44.58 & 0.84 \\
\hline
\end{tabular}

Table 10. Strongly correlated modes across pressure levels for vacuum test, $0.5 \mathrm{psig}$ and $0.75 \mathrm{psig}$ 


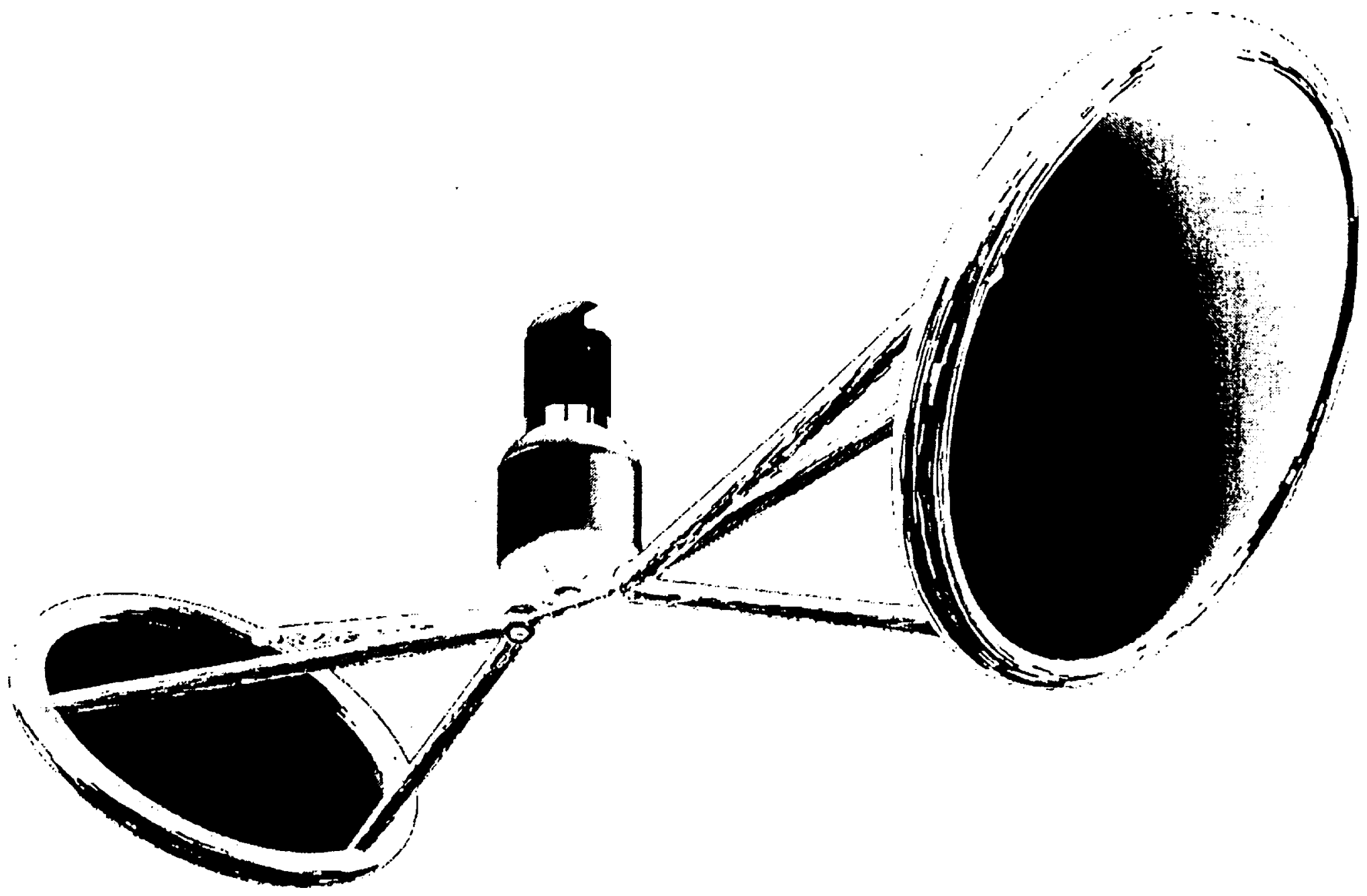

Figure 1. Conceplual drawing of Solar Thermal Upper Stage (STUS) 


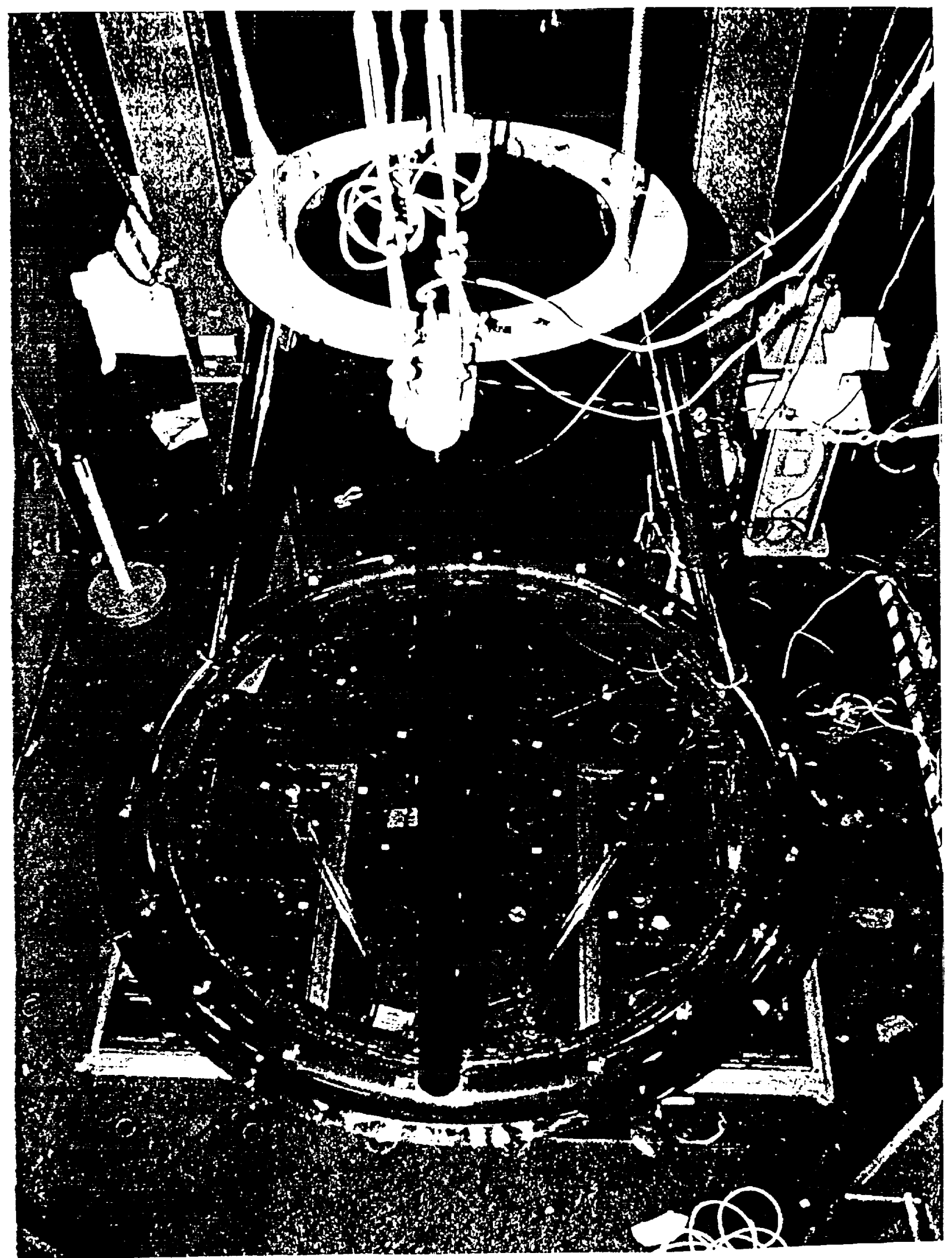

Figure 2. Pahimater isudate 


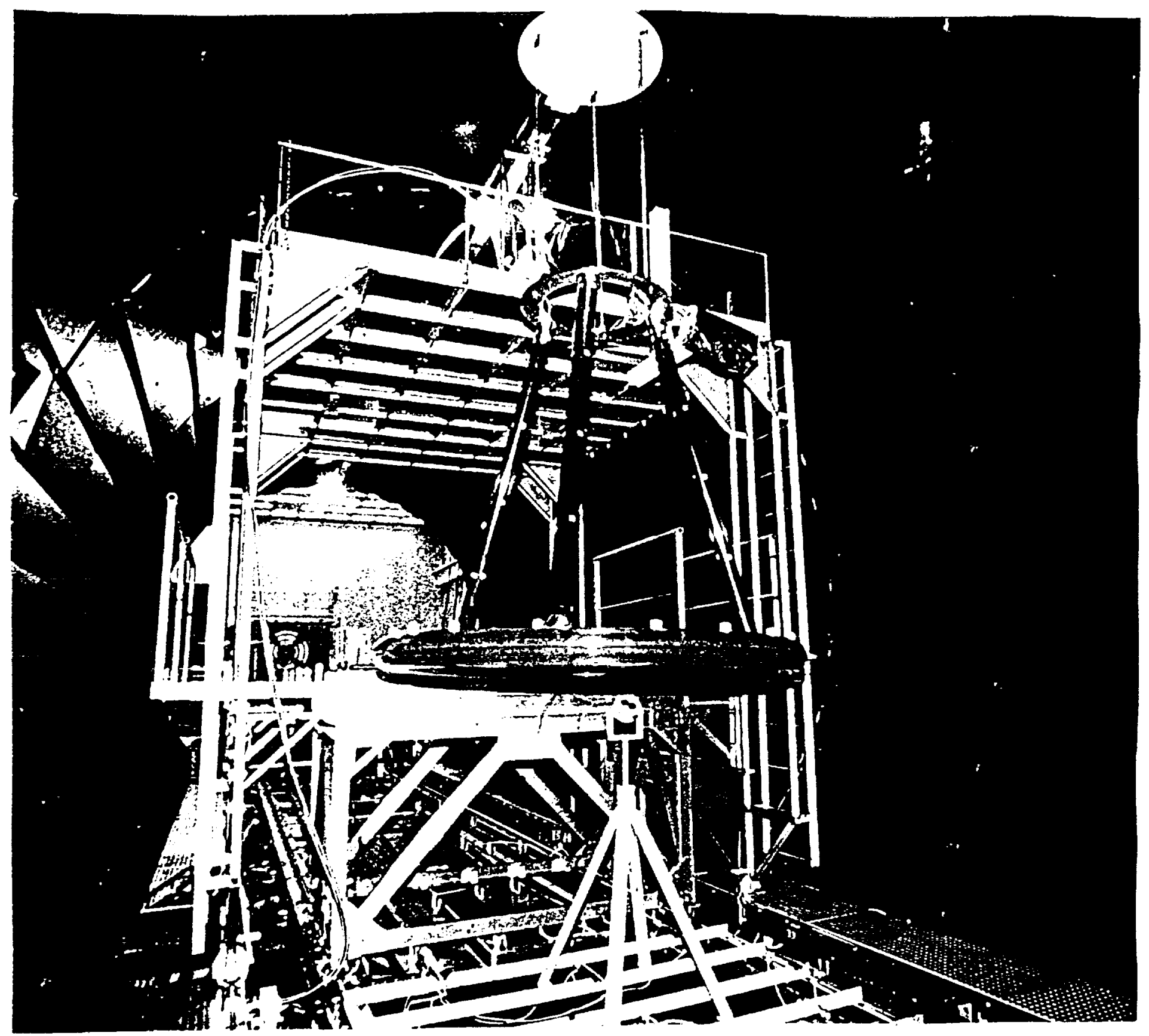

Figure 3. Pathninder 3 test articte in X-Ray Calibration Facility (XRCF) vacuum chamber 


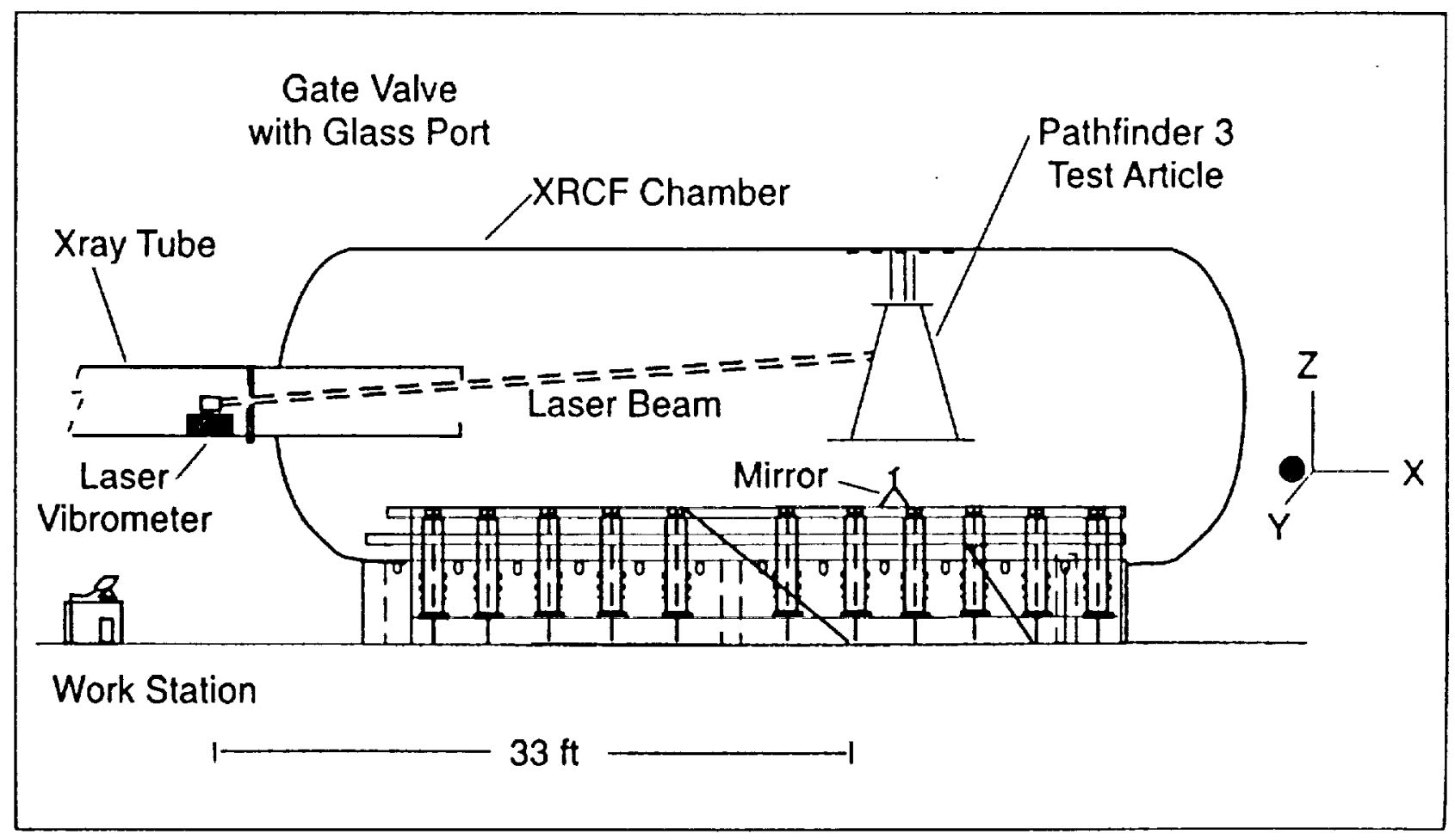

Figure 4. Diagram showing vibrometer location relative to test article in XRCF 


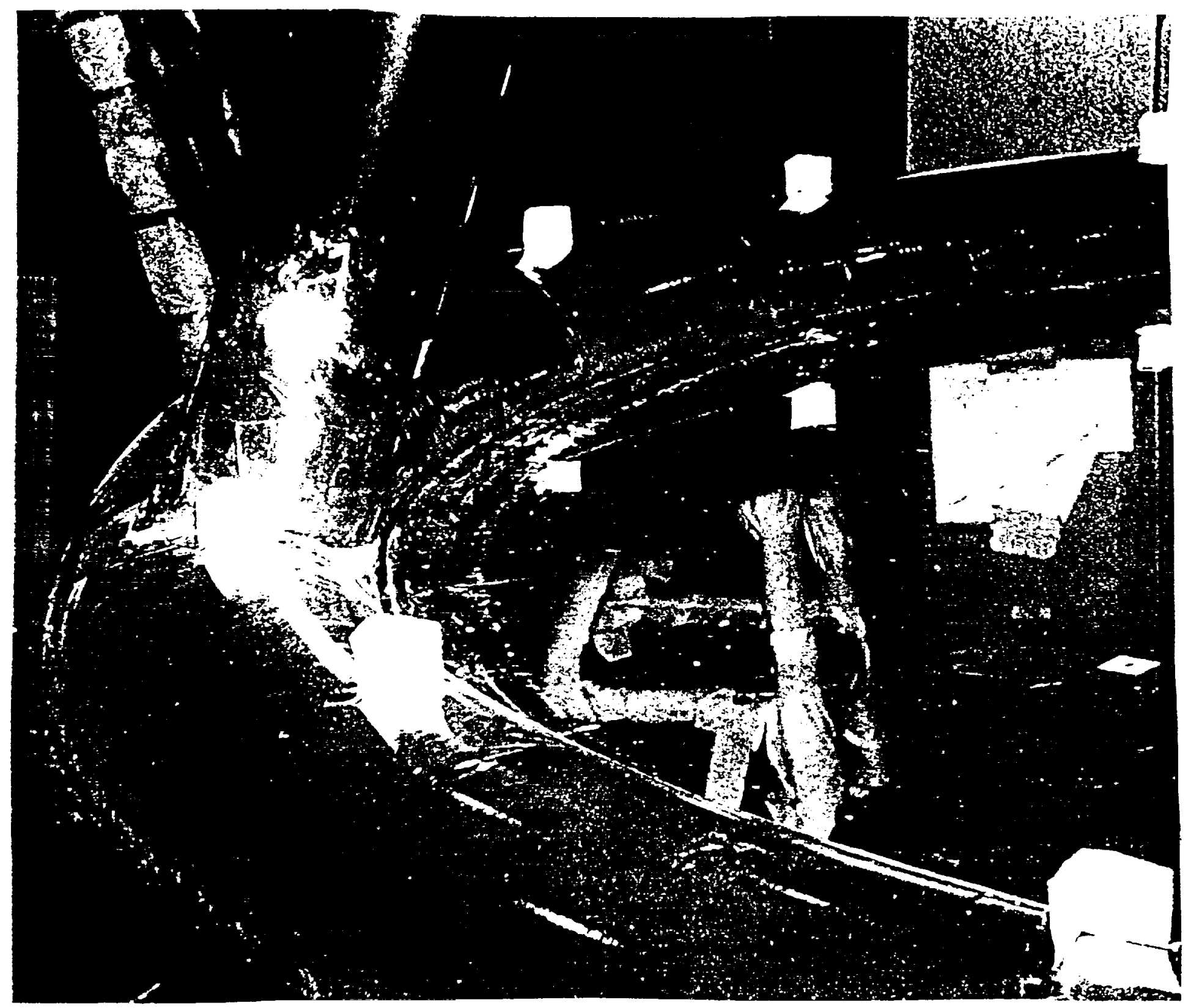

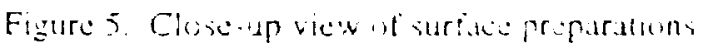



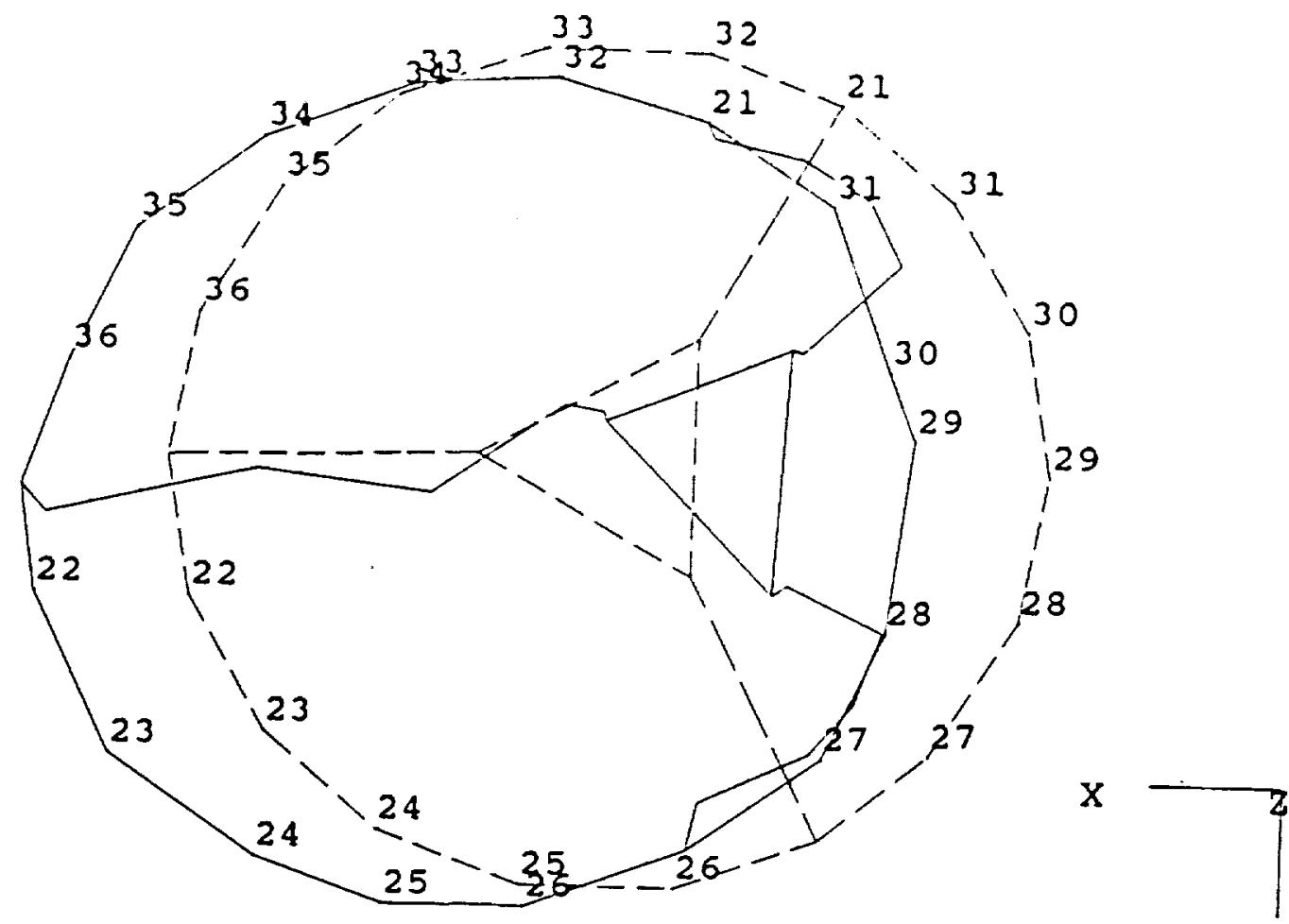

$Y$
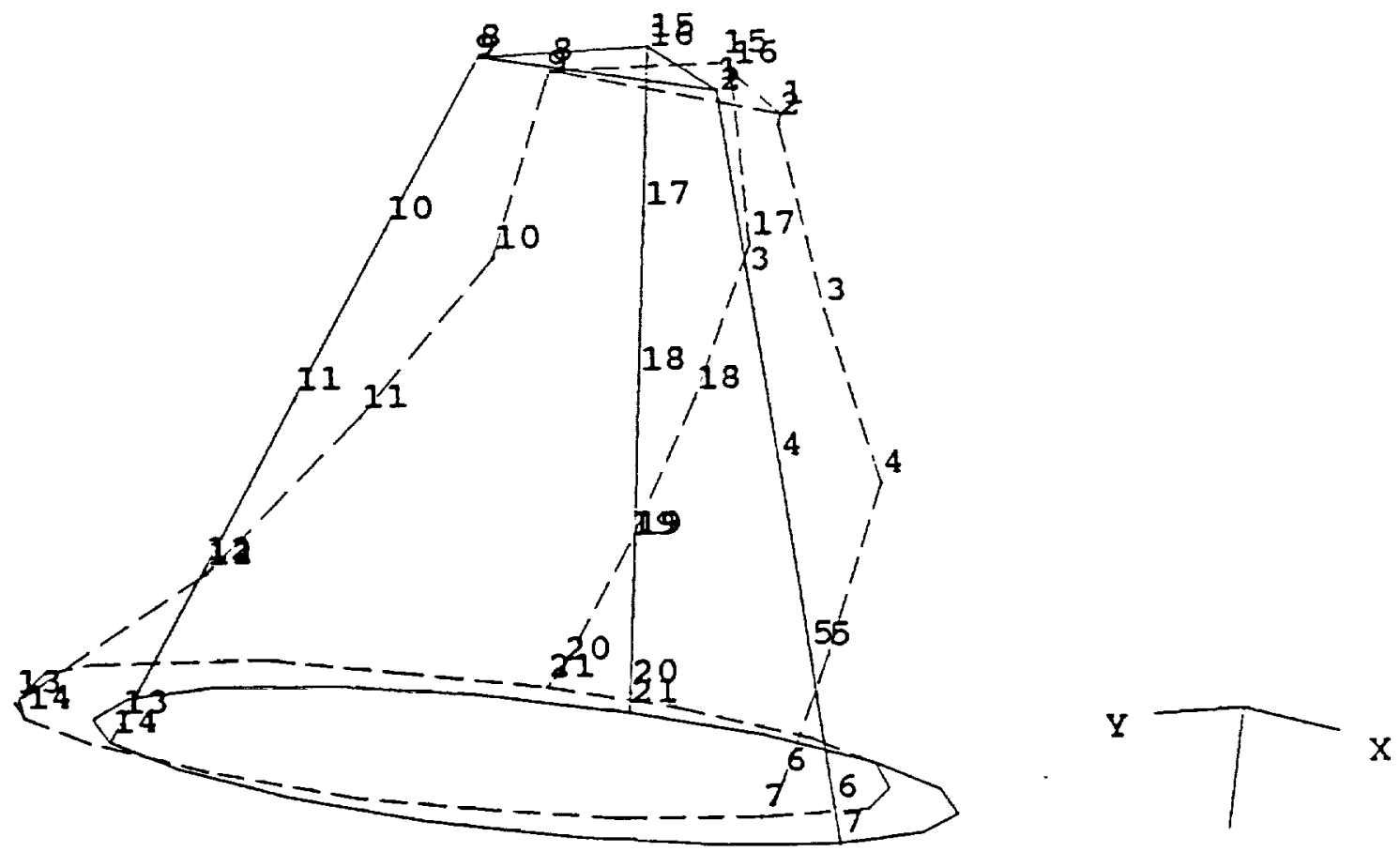

Z

Figure 6. Third mode of vacuum test case A $\left(0.5\right.$ psig. $\left.70^{\circ} \mathrm{F}\right), 5.66 \mathrm{~Hz}$ 

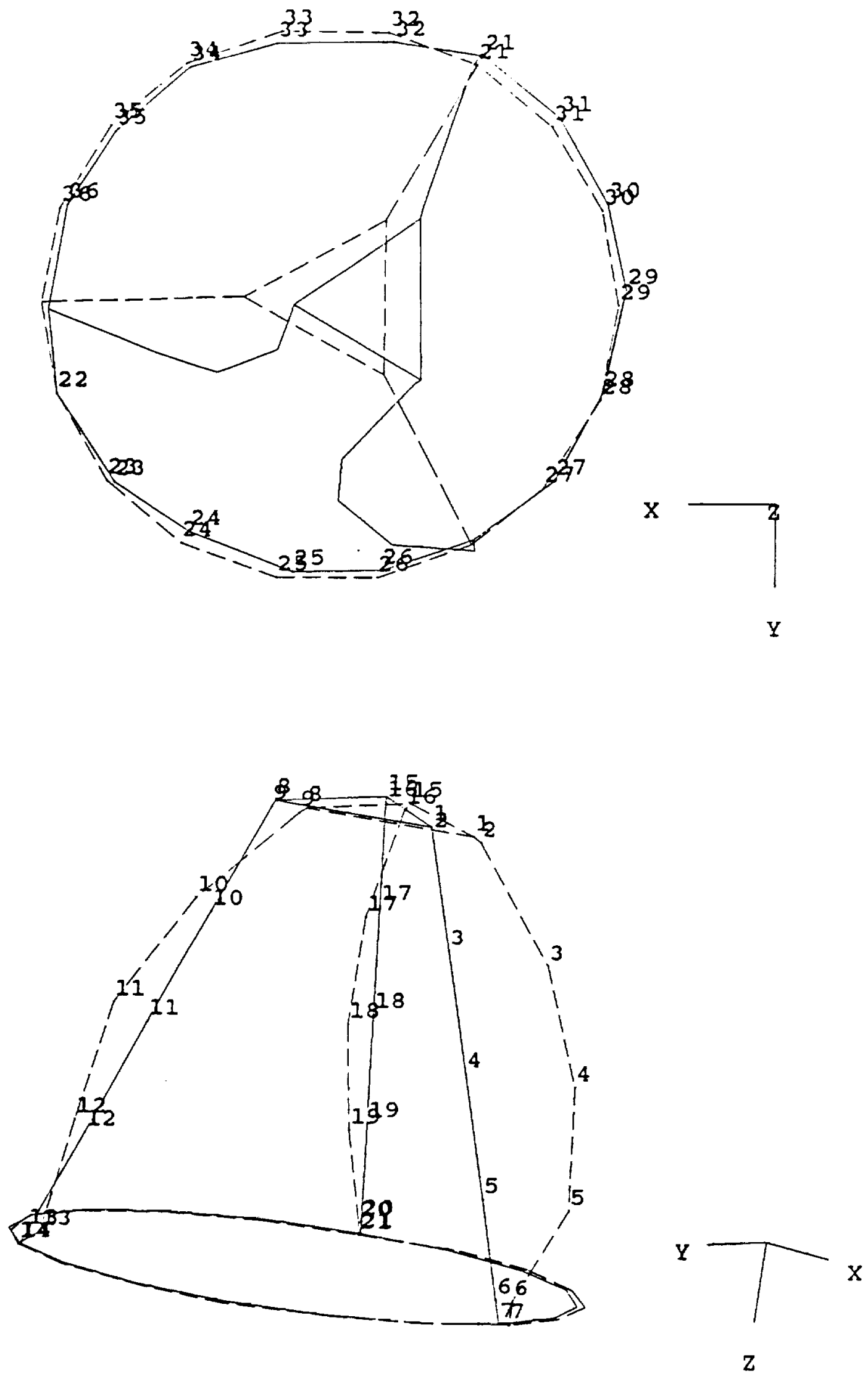

Figure 7. Seventh mode of vacuum test case A $\left(0.5\right.$ psig, $\left.70^{\circ} \mathrm{F}\right), 27.70 \mathrm{~Hz}$ 


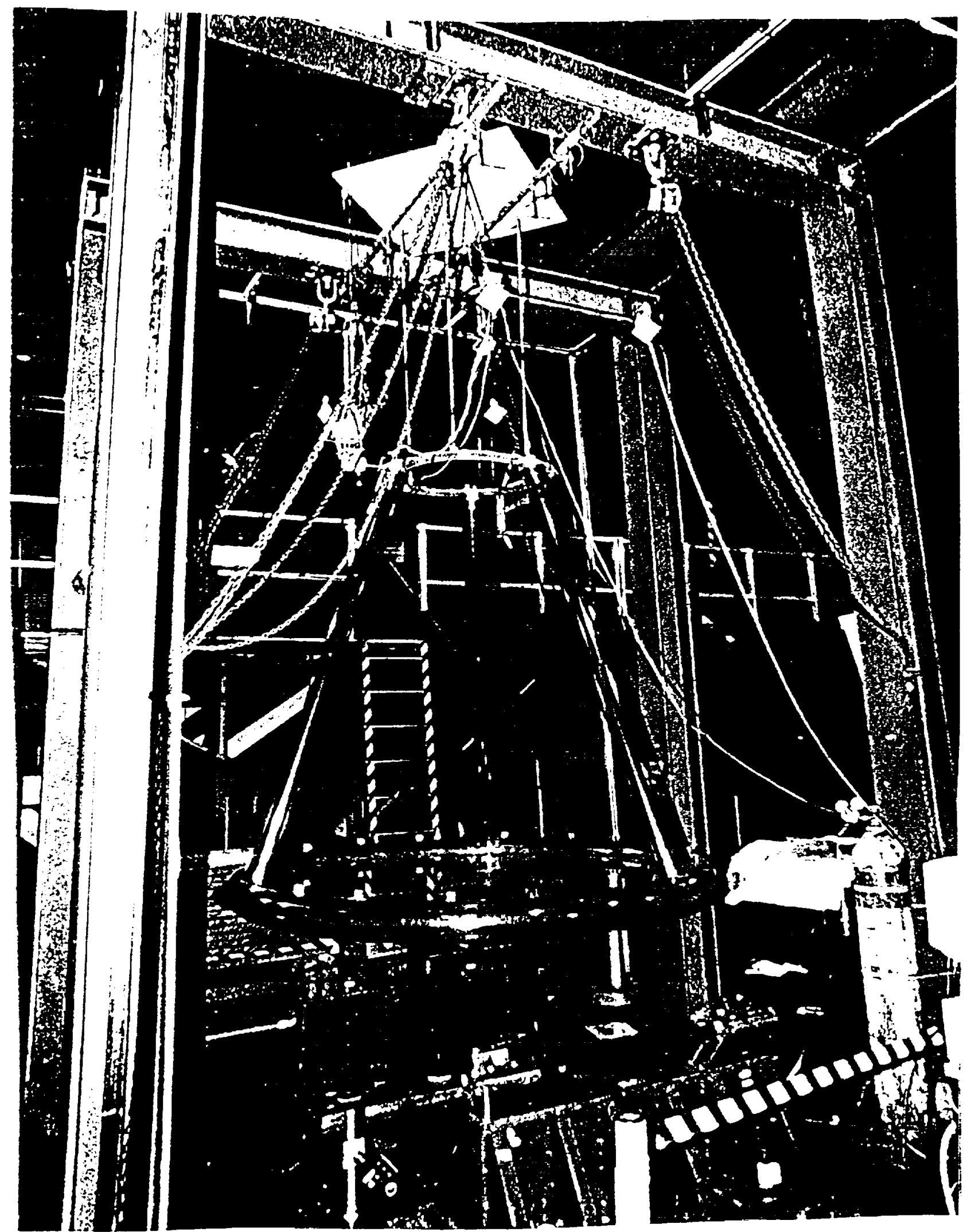



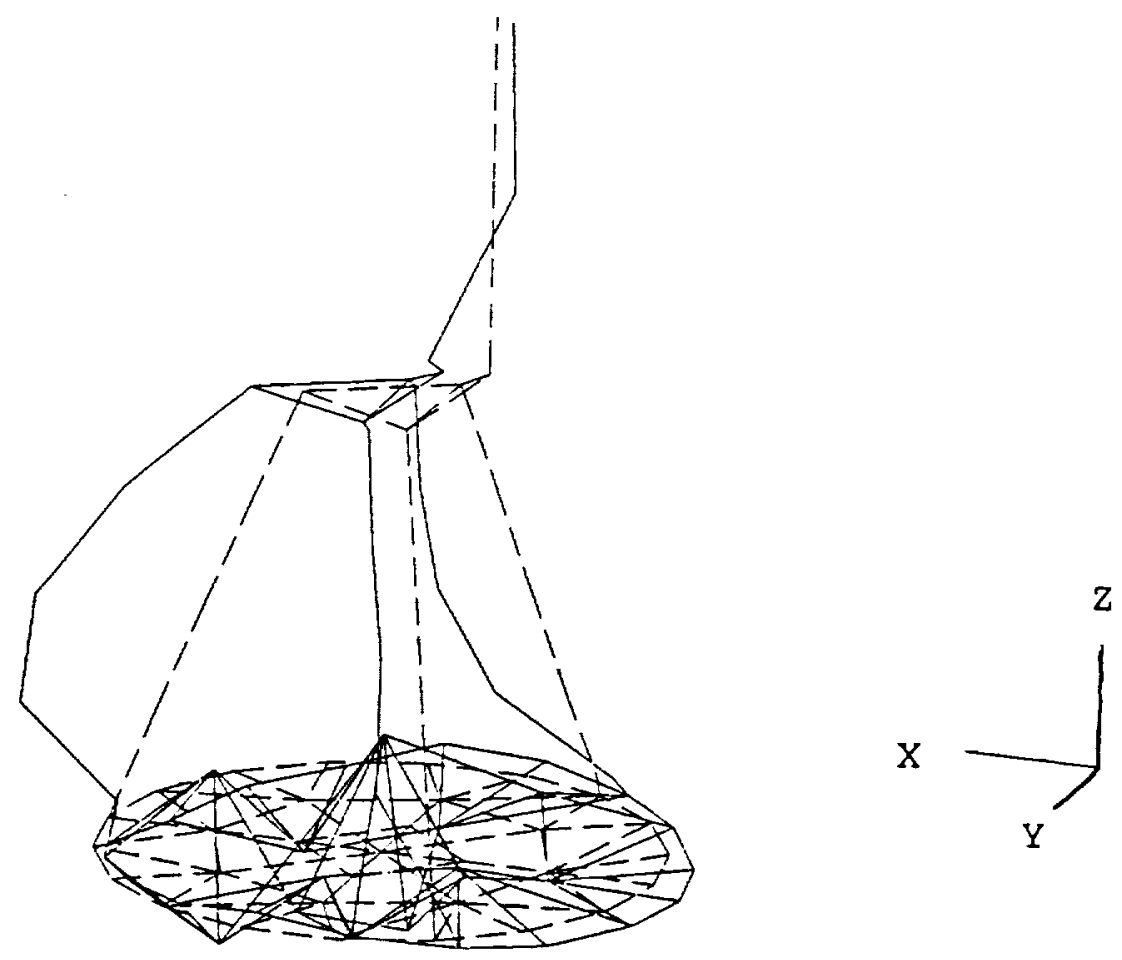

Figure 9. Ambient test, excitation in X direction, mode $6(24.73 \mathrm{~Hz})$ 


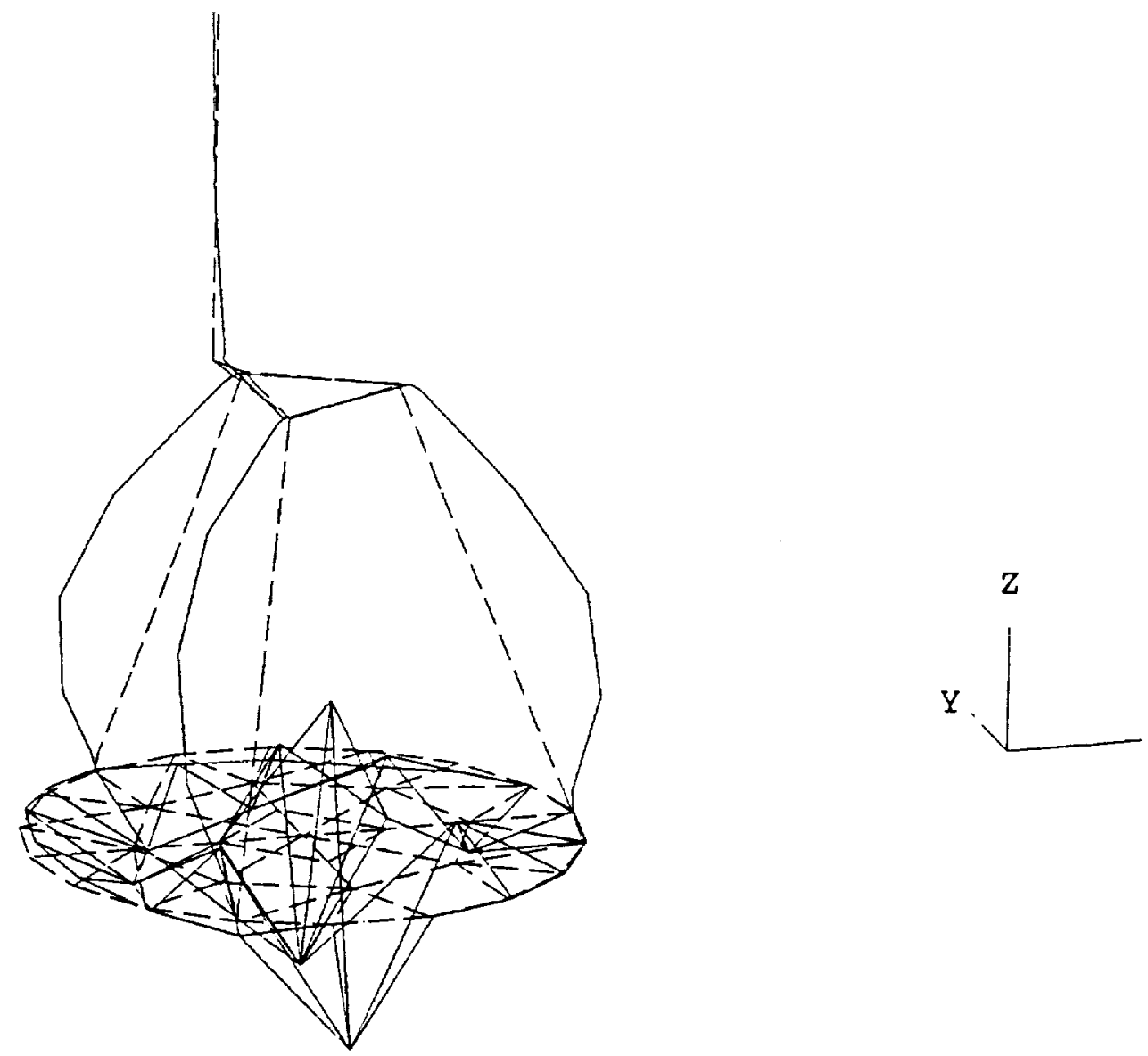

Figure 10. Ambient test, excitation in $\mathrm{Z}$ direction, mode $7(24.53 \mathrm{~Hz})$ 

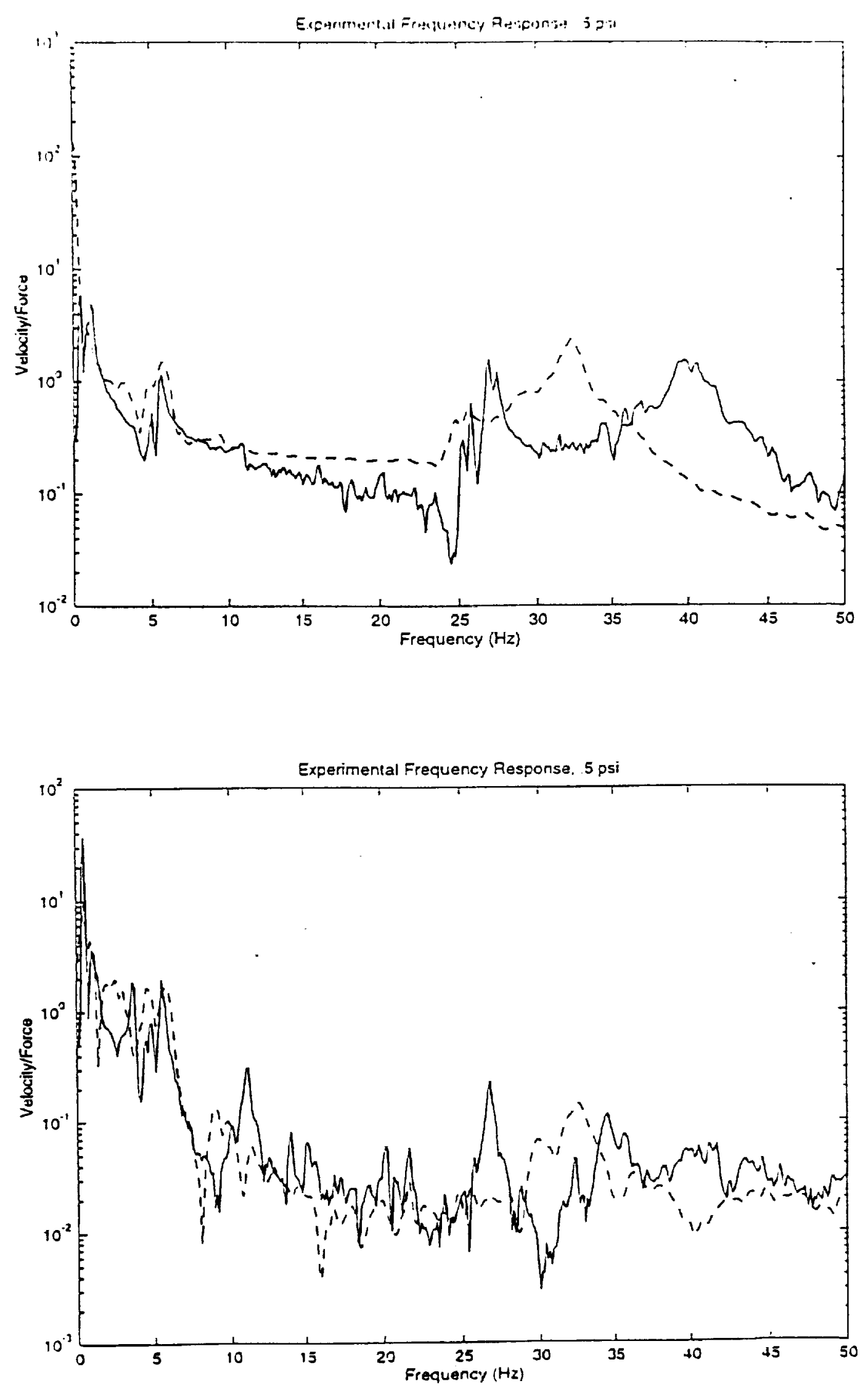

Figure 11. Frequency response functions for (top) measurement point on strut and (bottom) measurement point on torus, vacuum test pressure $0.5 \mathrm{psig}$, ambient test pressure 0.5 psig 

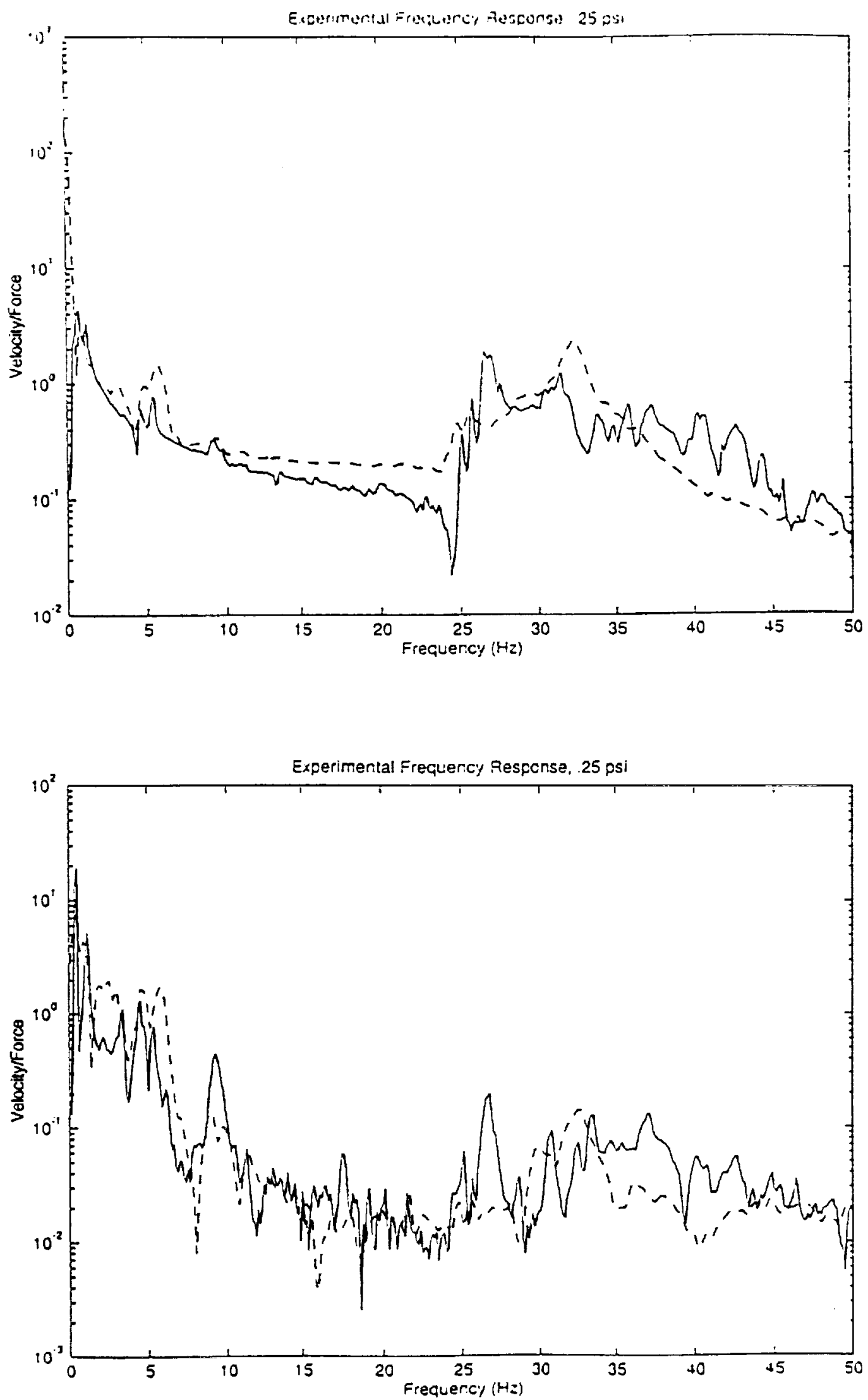

Figure 12. Frequency response functions for (top) measurement point on strut and (bottom) measurement point on torus, vacuum test pressure 0.25 psig, ambient test pressure 0.5 psig 

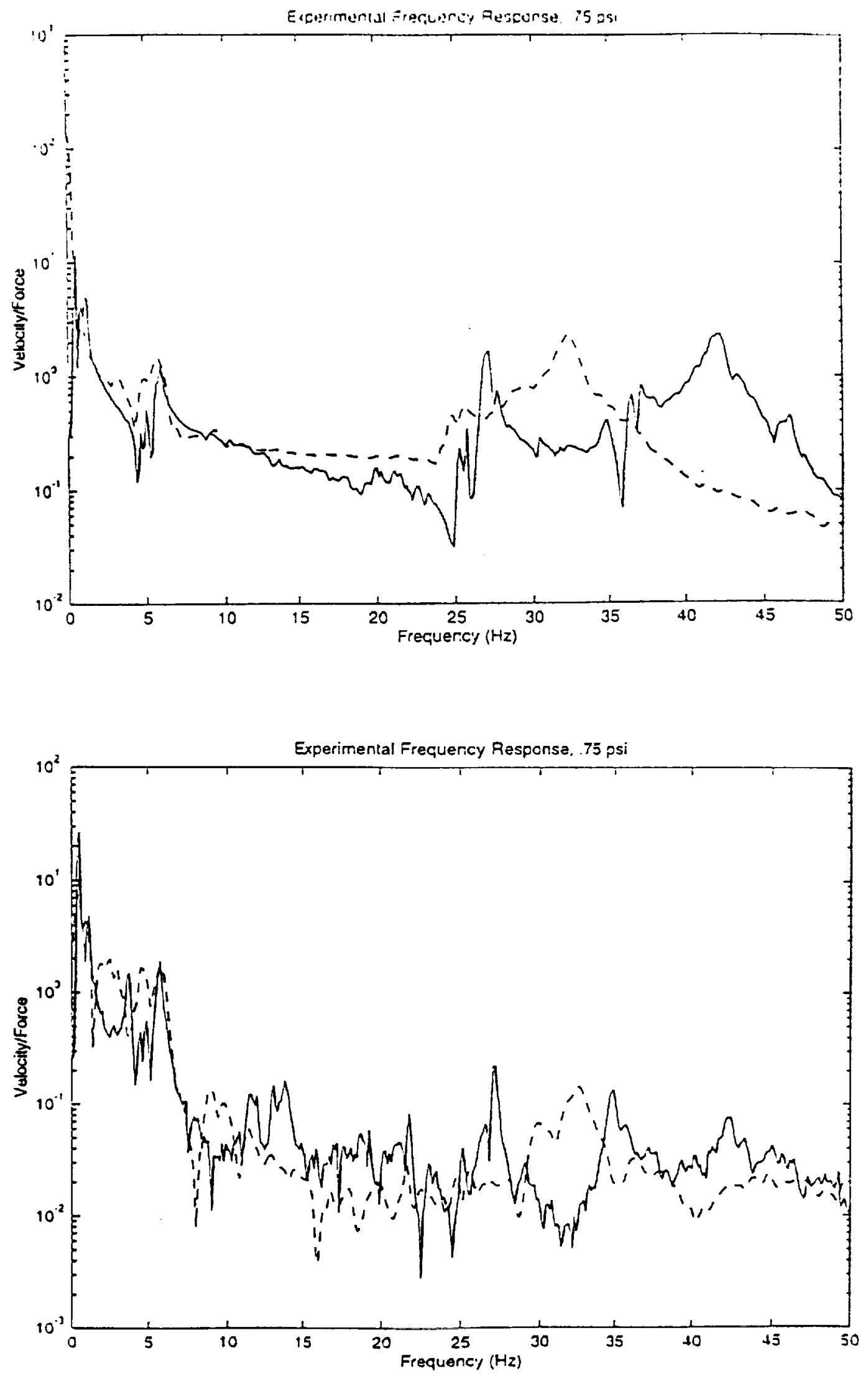

Figure 13. Frequency respunse functions for (top) measurement point on strut and (bottom) measurement point on torus, vacuum test pressure 0.75 psig, ambient test pressure 0.5 psig 


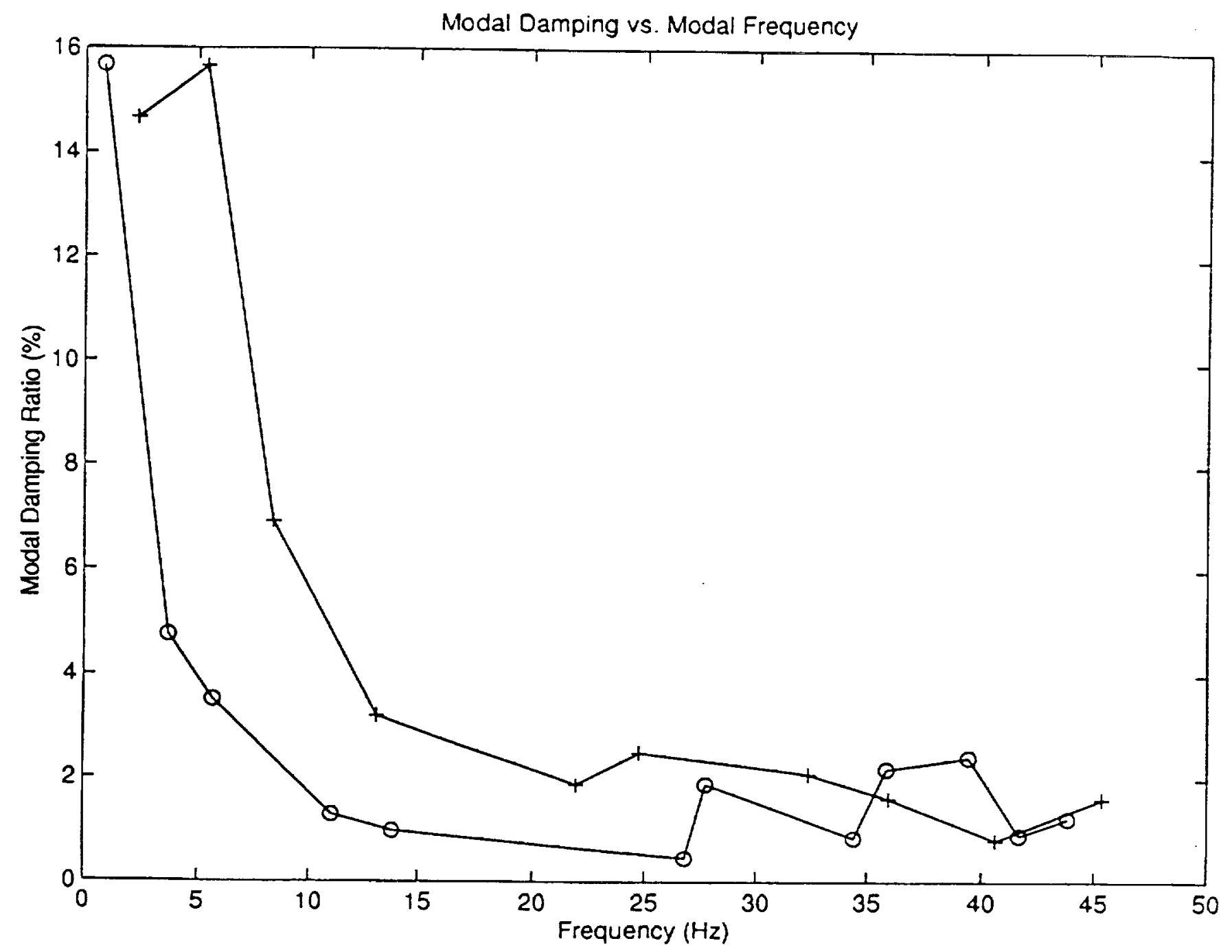

Figure 14. Modal damping vs. frequency, vacuum test pressure 0.5 psig. ambient test pressure 0.5 psig 


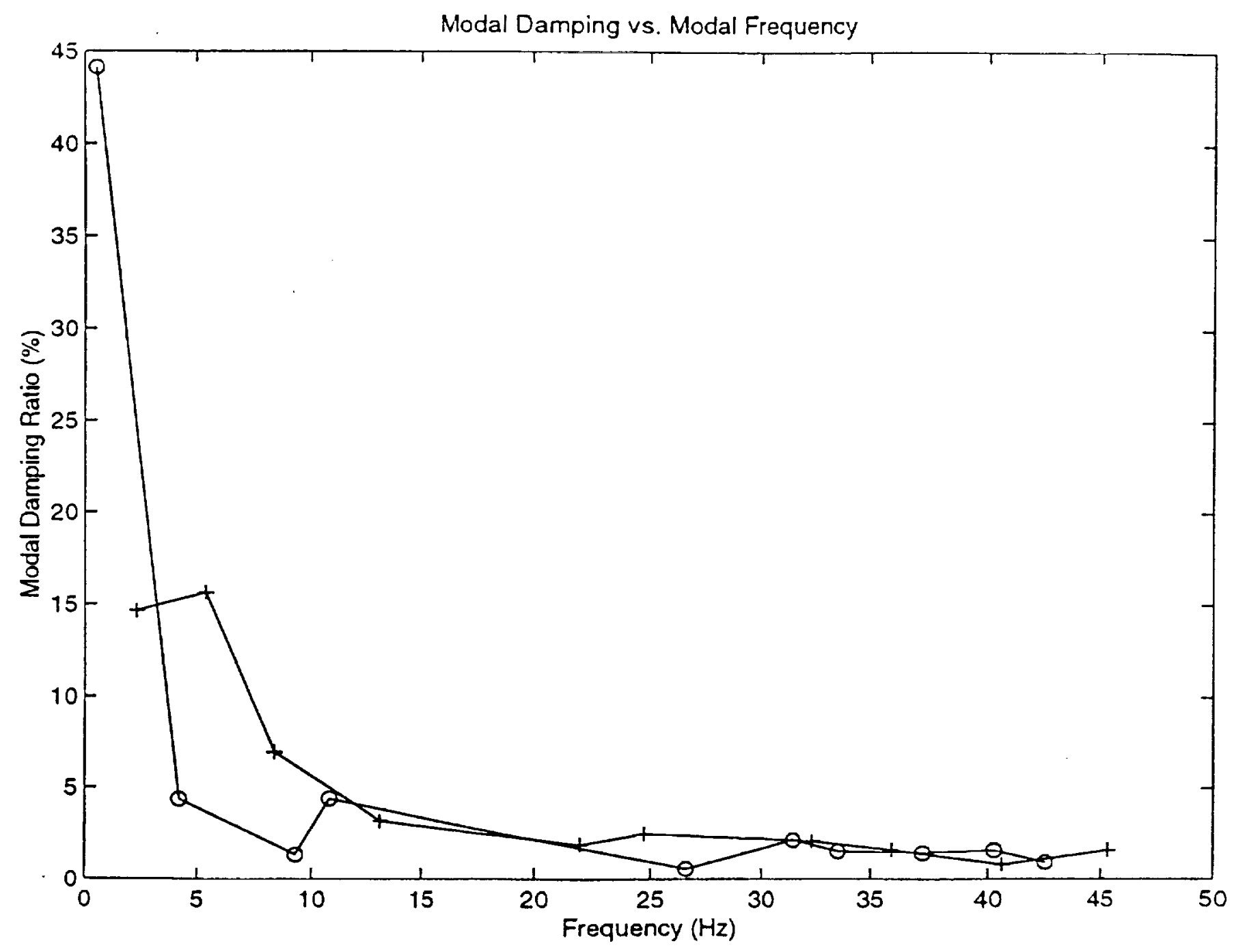

Figure 15. Modal damping vs. frequency, vacuum test pressure 0.25 psig. ambient test pressure 0.5 psig 


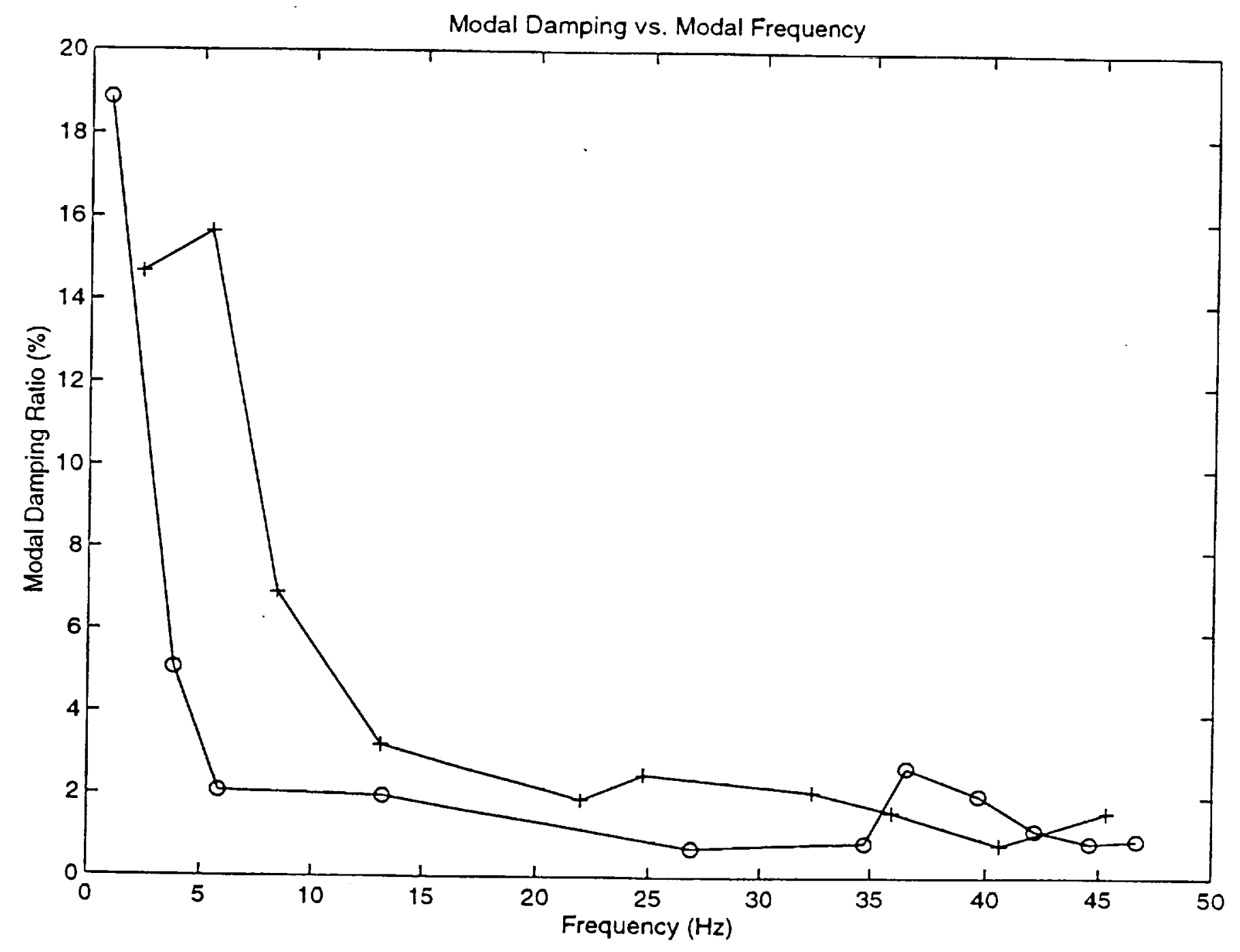

Figure 16. Modal damping vs. frequency, vacuum test pressure 0.75 psig. ambient test pressure 0.5 psig 


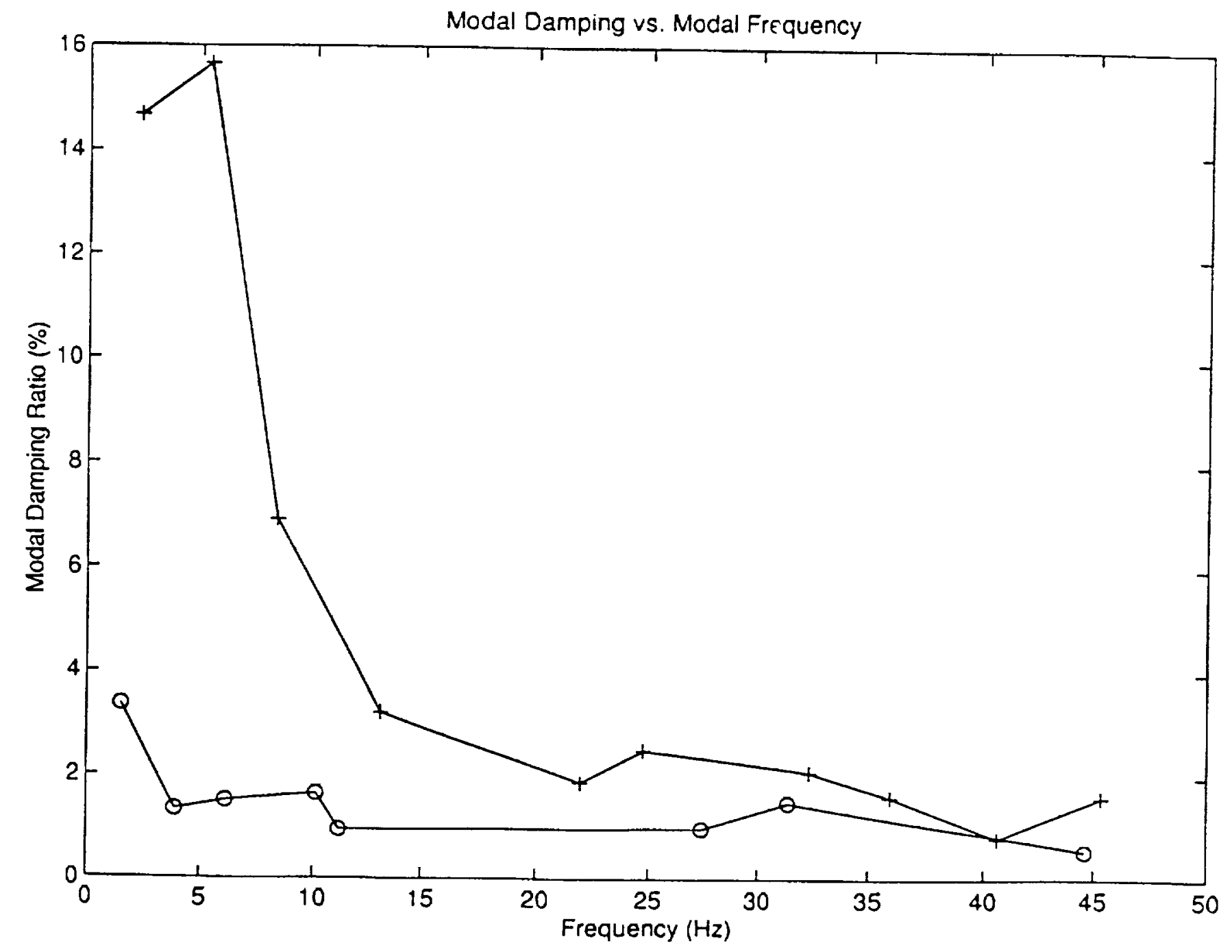

Figure 17. Modal damping vs. frequency, vacuum test pressure $0.5 \mathrm{psig}$. ambient test pressure $0.5 \mathrm{psig} . \mathrm{T}=-50^{\circ} \mathrm{F}$ 